NBER WORKING PAPER SERIES

THE IMPACT OF GROUP SIZE ON GIVING VERSUS DEMAND FOR REDISTRIBUTION

Johanna Mollerstrom

Avner Strulov-Shlain

Dmitry Taubinsky

Working Paper 29375

http://www.nber.org/papers/w29375

NATIONAL BUREAU OF ECONOMIC RESEARCH

1050 Massachusetts Avenue

Cambridge, MA 02138

October 2021, Revised October 2022

We thank the Foundations for Human Behavior at Harvard for funding. We are grateful to Christy Kang for excellent research assistance. We are grateful to Dan Houser, Ragan Petrie, and participants at the 2018 AEA meetings and the 2017 Science of Philanthropy Initiative conference for comments. The views expressed herein are those of the authors and do not necessarily reflect the views of the National Bureau of Economic Research.

NBER working papers are circulated for discussion and comment purposes. They have not been peer-reviewed or been subject to the review by the NBER Board of Directors that accompanies official NBER publications.

(C) 2021 by Johanna Mollerstrom, Avner Strulov-Shlain, and Dmitry Taubinsky. All rights reserved. Short sections of text, not to exceed two paragraphs, may be quoted without explicit permission provided that full credit, including $\odot$ notice, is given to the source. 
The Impact of Group Size on Giving Versus Demand for Redistribution

Johanna Mollerstrom, Avner Strulov-Shlain, and Dmitry Taubinsky

NBER Working Paper No. 29375

October 2021, Revised October 2022

JEL No. D63,D9

\begin{abstract}
We report the results of an online experiment studying preferences for giving and preferences for group-wide redistribution in small (4-person) and large (200-person) groups. We find that the desire to engage in voluntary giving decreases significantly with group size. However, voting for group-wide redistribution is precisely estimated to not depend on group size. Moreover, people's perception of the size of their reference group is malleable, and affects their desire to give. These results suggest that government programs, such as progressive tax-and-transfer systems, can help satisfy other-regarding preferences for redistribution in a way that creating opportunities for voluntary giving do not.

Johanna Mollerstrom

Vernon Smith Hall 5028

George Mason University

3434 Washington Blvd

Arlington, VA 22201

jmollers@gmu.edu

Avner Strulov-Shlain

5807 S Woodlawn Ave

Booth School of Business

Chicago, IL 60637

United States

Avner.Strulov-Shlain@ChicagoBooth.edu

Dmitry Taubinsky

University of California, Berkeley

Department of Economics

530 Evans Hall \#3880

Berkeley, CA 94720-3880

and NBER

dmitry.taubinsky@berkeley.edu
\end{abstract}


"I know well many of the mega-rich and, by and large, they are very decent people. They love America [...] and most wouldn't mind being told to pay more in taxes [...]. It's time for our government to get serious about shared sacrifice." (Warren Buffet in the New York Times, 2011)

"Wealthy people saying they want [...] to raise their taxes are just being politically hypocritical. Just pay more taxes right now if you want to. There is nothing stopping you." (Morgan Stanley wealth manager Frank Hill, in the North State Journal, 2019)

Many high-income individuals support more progressive tax and transfer policies that would decrease inequality but lower their own consumption (O'Brien, 2021). A common critique of the wealthy's support for redistribution is that they can instead make voluntary charitable donations, without government intervention. The U.S. federal government, for example, allows direct donations to itself. Thus, some deride the demand for higher taxes as hypocritical, as illustrated in the second quote above.

Does the apparent divergence between support for redistributive policies and voluntary giving reflect a fundamental feature of people's other-regarding preferences? An expansive and influential experimental literature has studied prosocial behavior, typically focusing on voluntary giving in one-on-one interactions or small groups. The small group sizes considered in this literature limit the extent to which it is informative about people's preferences for redistributive policies versus individual giving in large societies. The small group sizes considered in this literature might also be a reason why voluntary giving in laboratory experiments appears to be more prominent than voluntary giving in the field.

This paper addresses the gap by studying how people's propensity to engage in individual giving versus vote for group-wide redistributive policies varies with group size. While in small groups voluntary giving and support for group-wide redistribution are mechanically similar, we find that they diverge dramatically in larger groups. In particular, individual voluntary giving decreases significantly with group size, whereas support for redistributive policies does not.

In our online Amazon Mechanical Turk (MTurk) experiment, a total of 1,600 participants made incentivized choices as "rich" players, in groups with an equal number of rich and poor players. The "rich" were endowed with 350 cents and the "poor" were endowed with 10 cents. We varied two key dimensions of the decision-making environment.

First, half of our participants were part of small groups of 4 people, whereas the other half were in groups of 200 participants. This was varied between participants. Second, we introduced within-subject variation in the types of giving/redistribution decisions. The first type involved an option for individual giving, with the gift distributed equally among all of the poor participants. The second type involved an individual giving decision where the gift would be assigned to one randomly chosen poor participant (but in such a way that no poor participant received a gift from more than one rich participant). We call both of these first two types of decisions "individual giving" because a participant's decision to give does not affect transfers from other rich participants. This 
is in contrast to our third type of decision, where the rich participants voted on whether a transfer should be made from all rich participants to all poor participants.

Additionally, we varied the cost of transfers to the poor within-subject, so that each participant took part in a total of 9 decisions: 3 decision types $\times 3$ different costs of giving. Finally, we varied the framing of the voluntary giving to one participant. In one frame we described the recipient as a "matched partner" while in another frame we described the recipient as a "randomly selected person." This manipulation, which merely altered the language in which the other person was described, was conducted to test the malleability of perceived group size; in particular to test whether participants in larger groups might behave as if they perceive themselves to be in a small group of two when the recipient is described as a "matched partner," and thus are more willing to give.

While the four different types of other-regarding decisions - ranging from voting on redistribution to giving to one partner - are not directly comparable, this was by design. The main goal of the experiment was not to compare decisions for a given group size, but rather to study and compare comparative statics with respect to group size in each of these types of decisions.

Our main finding is that while participants' propensity to vote for group-wide redistribution does not vary at all with group size, their propensity to engage in individual giving that is not to "a matched partner" declines significantly with group size. Consequently, participants are significantly more likely to vote for group-wide redistribution than they are to engage in individual giving, when the individual gift is designated to be split evenly among all poor participants, or when it is designated to one "randomly selected person." A secondary finding is that participants' propensity to give to "a matched partner" is statistically indistinguishable from their propensity to vote for group-wide redistribution, both in small and large groups. This implies that perceptions of group size are not only a key driver of individual giving, but are also malleable.This in turn suggests that a reason for the significant voluntary giving in many laboratory experiments is the design/frame that suggests to participants that they are in a small group.

Our results inform theories of social preferences. For example, if people are motivated by "warm glow" (e.g., Andreoni, 1990, Andreoni, 1993, Andreoni, 1995) or a need to satisfy moral obligations (Rabin, 1995) that is based only on the degree of personal sacrifice, then their willingness to make a sacrifice through individual giving versus through a more progressive tax could be identical. On the other hand, if people trade off preferences for more equal distribution of resources within groups against their own material self interest, then in large groups they may be more willing to support a centralized redistributive policy than to engage in individual giving. The reason is that a centralized redistributive policy can have a larger impact on the group-wide allocation at the same cost to oneself. We formally show that our results are inconsistent with several prominent models of social preferences, but we formalize a class of models that is consistent with all of our results. The preferences introduced in Andreoni and Miller (2002), Fisman et al. (2007), and Andreoni (2007) are special cases of the framework that we formalize.

Our results suggest that centralized redistributive policies, such as progressive tax-and-transfer 
systems, can help satisfy other-regarding preferences for society-wide redistribution that opportunities for individual giving cannot. This is because our results imply a form of other-regarding preferences where equitable allocation of resources is an intrinsic public good-but like most "standard" public goods it can more easily be attained through a collective action mechanism because the incentives for voluntary contributions are too weak, especially in large groups.

Our results extend a small but distinguished literature on group size effects in the laboratory. Isaac and Walker (1988) and Isaac et al. (1994) focus on experimental public goods games where individuals can contribute money to their group with a rate of return higher than one. They find that larger group sizes increase "free-riding" behavior when they increase the cost of cooperative actions (for partly contrasting results, see also Diederich et al., 2016 and Weimann et al., 2019). Carpenter (2007) shows that cooperative behavior can increase in large public goods games when punishment of free riders is possible, as free riders are more likely to be punished in larger groups. Because these papers focus on public goods games, they do not directly inform our central questions about the preferences for society-wide redistribution and voluntary giving. Methodologically, the focus on dynamics of positive and negative reciprocity - which partially depends on dynamicallyevolving beliefs about others' behavior - makes it difficult to benchmark our results on voluntary giving to this work.

Our paper complements Durante et al. (2014) and Fisman et al. (2021), who study preferences over group-wide allocations in groups of size 21 and 7, respectively, with the aim of better understanding people's preferences over redistributive public policy. The decisions in these papers are most similar to our participants' voting decisions about group-wide redistribution, but allow subjects to express more nuanced preferences over the allocation of resources. We complement this work by contrasting group-wide allocation decisions with individual giving decisions, and in particular by studying how this varies with group size. More generally, our paper sits in a larger literature that uses controlled experiments on social preferences to study people's attitudes toward redistributive policies (e.g., Fisman et al., 2015; Kuziemko et al., 2014; Charite et al., 2022).

Closer to our work are the experiments reported by Andreoni (2007), who studies group sizes between 2 and 10 participants, where the "dictator's" gift is equally split among the recipients. Consistent with our results, Andreoni (2007) finds that voluntary giving declines with group size. Our experiment extends Andreoni (2007) by studying the impact of group size on preferences for giving versus redistribution, and also by utilizing significantly larger group sizes. Additionally, our experiment considers voluntary giving where the gift is both split equally among many recipients or directed to a single participant and studies the malleability of perceived group size. ${ }^{1}$

The rest of this paper proceeds by explaining the experimental design in Section 1, reporting the results in Section 2, discussing potential implications for models of social preferences in Section 3 , and concluding in Section 4.

\footnotetext{
${ }^{1}$ Relatedly, Schumacher et al. (2017) study a setting where a decision-maker makes choices about the provision of a good that benefits themselves or a receiver, but creates costs for a group of payers. They show that whereas some participants are sensitive to the size of a group of payers, there are others who are insensitive, and hence indifferent to the larger costs incurred when the payer group is larger.
} 


\section{Experimental Design and Implementation}

Our experiment was run on Amazon Mechanical Turk (MTurk) in April and June of 2017 on a total of 1,600 participants ${ }^{2}$. Our eligibility criteria were that participants had to be at least 18 years old, have a US or Canadian postal address, and have a favorable rating from at least 95 percent of at least 50 previous tasks on MTurk. A key advantage of large online platforms such as MTurk is the ability to create large group sizes. Another advantage is that participants can be assigned to group sizes completely randomly, rather than at the "session level," which implies that in our statistical analyses standard errors need only be clustered at the participant level, rather than the group level.

Half of the participants were randomly assigned to be in a group of 4 participants, while the other half were randomly assigned to be in a group of 200 participants. Appendix Table A3 shows covariates balance between participants assigned to large and small groups. Each participant was randomly, and with equal chance, assigned to be either an A player, with an initial endowment of 350 cents, or a B player, with an initial endowment of 10 cents. We used the strategy method (Selten, 1967; Brandts and Charness, 2011) and did not initially reveal the assignments to A versus $\mathrm{B}$, instead asking each participant what they would do if they were assigned to be the A player. The strategy method allowed us to maximize data collection without impacting participants' incentives. In the experiment, we referred to the two different roles exclusively as "A player" and "B player," but in the paper we refer to these as "rich" and "poor," respectively.

Screenshots of the full experiment are contained in Appendix C.

Decisions Participants made three sets of decisions, with each set consisting of three decisions. The three sets were randomly ordered, and likewise within each set the three decisions were randomly ordered. Figure 1 summarizes these three sets of experimental decisions, which we now explain in detail.

We refer to the first set as giving to many. In these three decisions, the rich participants chose whether to give up $X \in\{80,100,120\}$ cents to generate a transfer of 100 cents that would be divided equally among the poor players in their group. In small groups, this would entail transfers of 50 cents to each of the poor players, while in large groups this would entail a transfer of 1 cent to each of the poor players. Each of the three different values of $X$ corresponded to a decision in this set.

We refer to the second set of three decisions as giving to one, and we label the two variations of this set as giving to one of many and giving to one partner. In these decisions, rich participants had to choose whether to give up $X \in\{80,100,120\}$ cents to generate a transfer of 100 cents to a single poor player. It was explained that "the computer will make sure that no B-player can get more than 100 cents." In the giving to one of many variation, we used language that encouraged participants to think of themselves and their partner as part of the larger group: "Do you want to spend $[X]$ of your 350 cents to increase a random one of the B-players' payoff by 100 cents?"

\footnotetext{
${ }^{2}$ This study is registered in the AEA RCT Registry. DOI: "10.1257/rct.8346-1.0".
} 
In the giving to one partner variation, we used language that encouraged participants to think of themselves and their partner as part of their own group: "Do you want to spend $[X]$ of your 350 cents to increase your paired B player's payoff by 100 cents?"

We refer to the third set of decisions as voting on redistribution. In these decisions, each of the rich players voted on whether or not all of the rich players would have to give up $X \in\{80,100,120\}$ cents to increase each of the poor player's payout by 100 cents. If half or more of the rich players voted in favor, redistribution would be implemented.

After the three sets of decisions as a rich player, participants made a single decision about what they would want to do if they were assigned to be in the role of a poor player. The poor players could vote to decrease the rich players payoffs by 100 cents, without any benefit to themselves, and this would be implemented if at least half of the poor players voted to support this policy. This decision was of secondary interest in our analysis, which is why it was not presented in random order. It was included for purposes of studying the extent to which "behindness aversion" models, such as Fehr and Schmidt (1999), could explain our results.

In the very last decision, participants took part in a standard dictator game where the "dictator" chose how to allocate 100 cents between themselves and a partner. While each participant had a 50 percent chance of being the dictator, they did not learn the assignment initially and first had to make a decision about how they would allocate the money in the event that they are assigned to be the dictator. This last decision was also not presented in random order relative to the other decisions because it is not of primary interest to our analysis. Instead, we use behavior in this decision to classify participants as more or less prosocial in various robustness analyses of the primary experimental decisions.

Incentive compatibility Within each group, one of the ten decisions - nine primary decisions made by the rich players and the poor players' vote about whether or not to simply reduce the payoffs of the rich players - was selected to determine the outcomes for the group. The likelihood of each possibility was 10 percent, and the outcome was applied to all participants within a group. Thus, it was incentive-compatible for participants to indicate their preferences in each decision truthfully, which was explained to them. The bonus dictator game involved separate and additional payoffs.

Comprehension questions Prior to participants making any decisions, we asked five comprehension questions about the number of group members, of A-player's and B-players respective endowments, and about which role participants would start answering questions in.

Demographics At the very end of the experiment, participants were asked about their age, gender, ethnicity, country of residence, marital status, income, education, and political views. 


\section{Results}

We limit our primary analysis to participants whose behavior satisfies two key checks for engagement with our experiment. First, we limit analysis to the 92.5 percent of participants who correctly answered all five comprehension checks. Second, we limit analysis to the 88.3 percent of the remaining individuals whose decisions were monotonic, meaning that within each of the three sets of decisions, the participant was not more likely to give or vote for redistribution at a higher price than at a lower price. This leaves a total of 1307 participants for the main analysis. Appendices A.1 and A.2 show that our results are very similar in the full 1600-person sample and in the 92.5-percent-sample who passed comprehension checks.

\subsection{Descriptive Results}

Figure 2 summarizes behavior in the different decision sets by group size. Approximately 50 percent of participants voted for redistribution, and this share is almost identical between large and small groups: $48.9(\mathrm{SE}=2.0)$ percent in large groups and $50.9(\mathrm{SE}=1.9)$ percent in small groups.

Substantially fewer participants chose to give in the giving to many decision set, especially in large groups. $33.4(\mathrm{SE}=1.6)$ percent chose to give in small groups, and 15.1 ( $\mathrm{SE}=1.2)$ chose to give in large groups. The difference in giving between large and small groups is a large and statistically significant 18.3 percentage points $(\mathrm{SE}=2.0) .^{3}$

Behavior in the giving to one of many decision set falls in between behavior in the giving to many and voting on redistribution decision sets. $43.1(\mathrm{SE}=2.2)$ percent chose to give in small groups - slightly less than the fraction of people voting for redistribution - and 34.4 ( $\mathrm{SE}=2.0)$ chose to give in large groups. The effect of group size in this decision set is a statistically significant 8.7 $(\mathrm{SE}=3.0)$ percentage points, but it is smaller than the effect of group size in the giving to many decision set.

The propensities for prosocial behavior in the giving to one partner and voting on redistribution decision sets are almost identical, and insensitive to group size. The share giving in the giving to one partner set is $48.7(\mathrm{SE}=2.2)$ percent in large groups and $50.6(\mathrm{SE}=2.1)$ percent in small groups. The fact that behavior in the giving to one partner decision set does not vary with initial group size suggests that this framing manipulation led people to adjust their perception of the relevant social group to one that only includes themselves and their partner, and that this leads to higher levels of giving.

Behavior in the giving to one partner decision set suggests a simple explanation of why there is more giving in the giving to one of many decision set than in the giving to many decision set. In the giving to one of many decisions some participants likely regard their relevant social group as only including themselves and the participant who will receive their transfer. Although we used language that highlighted the larger group, the nature of the decision and the prompt-which mechanically

\footnotetext{
${ }^{3}$ Standard errors for differences in this and other analogous summaries of Figure 2 results are calculated from inferences on the coefficients estimated in the regression described in the notes of Figure 2.
} 
drew attention to there being one other dependent individual-likely lead some participants to regard their relevant social group as only including that other individual in the giving to one of many decision set.

Figure 3 disaggregates the summary statistics in Figure 2 by the price of giving. Consistent with earlier results such as those of Andreoni and Miller (2002) and Fisman et al. (2007), participants are elastic to the price of giving. On average, participants are about 25 percentage points more likely to act prosocially when the cost of doing so is 80 cents rather than 120 cents. This effect of a 50 percent difference in price is slightly larger than the effect of increasing group size from 4 to 200 in the giving to many decision set, and is slightly smaller than the effect of moving from giving to many to voting on redistribution in large groups. Figure 3 also shows that there is no interaction effect between prices and group size in the voting on redistribution decision set. The lack of interaction indicates that participants do not prioritize aggregate efficiency in their decision making, as a giving price of 120, for example, causes an aggregate loss of 40 cents in the small group but 2000 cents in the large group.

The effect of giving price within the giving to many decision set is as strong as in the other decision sets, which mitigates the concern that giving is low in that condition because of a rounding heuristic where individuals round down the transfer received by each poor player to zero. While participants who perceive the benefit to the poor players to be zero would not be responsive to the price of giving, we find that they are. A second concern is that individuals are more likely to vote prosocially than to give because their vote might not necessarily determine their outcome and thus is a "cheaper" signal of prosociality. If this were true, then individuals would be more likely to vote prosocially in large than in small groups, because in a small group with two rich players a single vote for redistribution is much more likely to be pivotal. Yet, there is no group size effect on voting propensity, contrary to the "cheap signal" argument.

Robustness Appendices A.1 and A.2 replicate Figures 2 and 3, respectively, for the full sample of 1600 participants and for the sample of participants who correctly answered all comprehension questions but were not necessarily monotonic in all of their decisions. The results are largely identical.

\subsection{Regression Analysis and Further Hypothesis Testing}

Table 1 presents regressions that quantify the effect of group size and other experimental conditions on participants' willingness to redistribute resources to the poor players. In all specifications, the omitted category is the condition where participants in a small group are asked to vote for redistribution. The columns in the table differ in the subsample considered and/or the additional control variables used. Column 1 quantifies the differences between the averages summarized in

Figure 2; Column 2 adds controls for the price of giving and for the order in which the decision was made; Column 3 limits analysis to only the first decision set encountered by participants, so that the effects of experimental conditions are quantified solely in a between-subject comparison; Column 4 
limits results to participants who chose to give a positive amount in the dictator game at the end of the experiment, as the not-fully-self-interested individuals are most likely to change their behavior across the different experimental conditions; Column 5 combines the restrictions from Columns 3 and 4; Column 6 examines the robustness of Column 2 for controlling for demographics.

Starting with the effects of group size, the coefficient on "Large $\times$ Vote redistribution" quantifies the difference in voting behavior between large and small groups. This difference is a tightly estimated zero. The coefficient on "Large $\times$ Giving to many" is the difference between giving in large versus small groups in the giving to many condition. Consistent with the leftmost panel of Figure 2, increasing group size from 4 to 200 is estimated to have a dramatically negative effect of -33.1 to -44.5 percentage points on giving in this condition. The coefficient on "Large $\times$ Giving to one" is the difference between giving in large versus small groups in the giving to one of many condition. Consistent with the visual evidence in the second panel of Figure 2, increasing group size from 4 to 200 is estimated to have a large but less dramatic negative effect of -14.5 to -16.7 percentage points on giving in this condition. The coefficient estimates on "Large $\times$ Giving to one $\times$ Partner" imply that participants in large groups are 13.4 to 18.8 percentage points more likely to give in the giving to one partner than in the giving to one of many conditions. The effect of increasing group size from 4 to 200 in the giving to one partner condition is given by the sum of the coefficients in rows 6 and 7 minus the sum of the coefficients in rows 3 and 4 . Consistent with the visual evidence in Figure 2, this effect is estimated to be near zero, ranging from -0.7 ( $\mathrm{SE}=5.0)$ to $-7.1(\mathrm{SE}=5.3)$ percentage points.

Turning to other comparisons, participants in small groups are 11.5 to 17.3 percentage points less likely to act prosocially in the giving to many condition than in the voting on redistribution condition. The coefficient estimates on "Giving to one" imply that participants in small groups are 5.0 to 7.8 percentage points less likely to act prosocially in the giving to one of many condition than in the voting on redistribution condition. The coefficient estimates on "Giving to one $\times$ Partner" imply that participants in small groups are 5.5 to 12.8 percentage points more likely to give in the giving to one partner than in the instrumentally identical giving to one of many conditions. Summing the coefficients on "Giving to one $\times$ Partner" and "Giving to one" gives the difference in prosocial behavior in small groups between the giving to one partner and the voting on redistribution conditions. This difference ranges between 0.3 and 5.9 percentage points and is statistically indistinguishable from zero in all six regressions.

In addition to precisely quantifying the various patterns observed in Figure 2, the analysis in Table 1 shows that these effects are robust to (i) controlling for order and demographics, (ii) restricting to the first decision set encountered by participants, such that that only between-subject variation is utilized, and (iii) restricting to participants who are not classified as purely self-interested through their dictator game decisions. Although restricting to only the first decision set mechanically inflates standard errors, it has no distinguishable effect on coefficient estimates. Thus, there is no evidence that within-subject variation biases our results. Consistent with the logic that purely self-interested individuals cannot be affected by the conditions of our experiment, we find that 
restricting to dictator game givers amplifies the coefficient estimates.

Robustness Appendices A.1 and A.2 replicate Table 1 for the full sample of 1600 participants and for the sample of participants who correctly answered all comprehension questions but were not necessarily monotonic in all of their decisions. The results are largely identical.

Our results that within-subject and between-subject estimates are similar suggest that withinsubject variation of decisions did not introduce bias from anchoring on previous decisions. Appendix Figure A6 provides further evidence against anchoring on previous decisions by showing that dictator game decisions were virtually identical for participants in large and small groups.

Behindness Aversion In principle, one reason why participants may be more averse to give individually than to vote for redistribution is because of behindness aversion, in the sense of Fehr and Schmidt (1999). We assess the relevance of behindness aversion in our sample by using the second-to-last decision in our experiment: the poor players could vote to decrease the rich players payoffs by 100 cents, without any benefit to themselves, and this would be implemented if at least half of the poor players voted to support this policy. We find that only 11.5 percent of poor participants wanted to decrease the payoffs of rich participants at no cost to themselves, which suggests a limited role for behindness aversion. In Section 3, further developed in Appendix B, we show that other aspects of our data are also inconsistent with wide-spread behindess aversion among our participants.

\subsection{Individual Differences}

Individuals differed strongly in their prosociality in our experiment. Appendix Figure A5 presents a histogram of the number of prosocial choices, out of nine, made by participants in the three primary decision sets in the experiment. 35.7 percent of participants acted in a self-interested fashion in all 9 decisions, while 12.2 percent of participants wanted to transfer money to the poor players in all 9 decisions.

While participants' behavior differs significantly across the different conditions of our experiment, we nevertheless find a certain persistence in individual prosocial behavior throughout the experiment. For example, individuals who give in all three decisions of the giving to many condition are significantly more likely to also vote for redistribution. We quantify these relationships formally in Table 2 as follows. For each person $i$ and condition $k$, we compute the fraction $f_{i k}$ of the three decisions in which the person acted to increase the resources of the poor players. For any two conditions $k$ and $k^{\prime}$, we then report the correlation between $f_{i k}$ and $f_{i k^{\prime}}$. We find that all correlations are greater than 0.5 , with the correlation between giving to one partner and voting on redistribution as high as 0.88 . These results suggest that there is a stable prosociality trait that impacts behavior in all conditions, despite some conditions dampening the prosociality and others amplifying it. In the next section we present a framework consistent with this. 


\section{Implications for Models of Social Preferences}

We sketch a class of social preferences models that are consistent with our results, and discuss other popular models that are inconsistent. Consider an individual $i$ receiving payoff $\pi_{i}$, who perceives themself to belong to a group of size $n$. In the group a fraction $\mu\left(\pi_{j}\right)$ of individuals receive payoffs $\pi_{j}$ from a finite set. The individual has preferences over their own payoff and the distribution of payoffs in the whole group, inclusive of themselves. Let $G$ be a probability distribution that assigns probability $\mu\left(\pi_{j}\right)$ to payoff $\pi_{j}$, and let the individual's utility function be given by

$$
U_{i}\left(\pi_{i}, G, n\right)=\left(1-\varphi_{i}\right) u\left(\pi_{i}\right)+\varphi_{i} \sigma(n) v\left(G ; \pi_{i}\right)
$$

where $\varphi_{i}$ is the degree of prosociality, $\sigma(n)$ is a weakly increasing function, and $v\left(\cdot ; \pi_{0}\right)$ is a functional that describes a person's preferences over the allocations in their (perceived) group, holding their own payoff constant. In other words, $v$ is a "disinterested" social welfare criterion. Without additional assumptions, this representation of preferences is a generalization of the "social welfare preferences" formalized by Charness and Rabin (2002). Because preferences in (1) depend only on outcomes, they do not incorporate "warm glow" (e.g., Andreoni, 1990, Andreoni, 1993, Andreoni, 1995) or a need to satisfy moral obligations (Rabin, 1995).

The models studied by Andreoni and Miller (2002) and Fisman et al. (2007) for two-player decisions are a special case where $u\left(\pi_{i}\right)=\frac{\pi_{i}^{1-\rho}-1}{1-\rho}$ and

$$
v\left(G ; \pi_{i}\right)=\sum_{j} \mu\left(\pi_{j}\right) \frac{\pi_{j}^{1-\rho}-1}{1-\rho}
$$

The special case of $\rho \rightarrow \infty$ gives the Rawlsian preferences proposed in Charness and Rabin (2002), while the case where $\rho=1$ and $\varphi_{i} \equiv 1$ corresponds to efficiency-seeking preferences to maximize the sum of group payoffs. ${ }^{4}$ The specification in (2) also covers the specification adapted by Andreoni (2007), with $\sigma(n)=n^{\gamma} .5$ Finally, as we show in Appendix B, the Fehr and Schmidt (1999) model is a special case of (1) where $u\left(\pi_{i}\right)=\pi_{i}, \sigma(n)=n /(n-1)$, and

$$
v\left(G ; \pi_{i}\right)=-\sum_{j} \mu\left(\pi_{j}\right) \alpha \max \left(\pi_{j}-\pi_{i}, 0\right)-\sum_{j} \mu\left(\pi_{j}\right) \beta \max \left(\pi_{i}-\pi_{j}\right)
$$

Because participants are equally likely to vote for redistribution in both large and small groups, the results imply that $\sigma(n)$ is a constant in our general framework. To see this, first observe that group-wide redistribution has the same impact on $G$ in both large and small groups - in both cases it transforms $G$ from a distribution where 50 percent have $\$ 3.50$ and 50 percent have $\$ 0.10$ to a distribution where 50 percent have $\$ 2.50$ and 50 percent have $\$ 1.10$. Second, note that if $\sigma(n)$

\footnotetext{
${ }^{4}$ Andreoni and Miller (2002) and Fisman et al. (2007) write their models as $U_{i}=\left(\alpha \pi_{i}^{\gamma}+(1-\alpha) \pi_{j}^{\gamma}\right)^{1 / \gamma}$, which is equivalent to $U_{i}=\alpha \pi_{i}^{\gamma}+(1-\alpha) \pi_{j}^{\gamma}$. This is mathematically equivalent to our formulation if $\gamma=1-\rho$ and $\alpha$ satisfies $(1-\alpha) / \alpha=\varphi_{i} \sigma(2) /(1-\varphi)$.

${ }^{5}$ Schumacher et al. (2017) study group size effects using the formulation of Andreoni and Miller (2002).
} 
increased with $n$ then individuals would value this change in $G$ more in larger groups than in smaller groups, contrary to our results. A corollary of this reasoning is that if the giving to one partner condition leads participants to perceive themselves to be in a group of size 2 , then they should be just as willing to give in that condition as they are to vote for redistribution in the voting on redistribution condition; the reason is that both giving and voting in these respective conditions have the same impacts on $G$ and the same impacts on own payoff $\pi_{i}$.

When $\sigma(n)$ is constant in $n$ the model predicts that voluntary giving decreases with (perceived) group size. The reason is that a single individual's transfer has a smaller effect on $G$ in larger groups. For example, a $\$ 1$ transfer split equally among the poor in a group of size 4 changes $G$ from a distribution in which each of the poor have $\$ X$ (depending on other A players' actions) to a distribution in which each of the poor have $\$ X+\$ 0.50$. But a $\$ 1$ transfer in a group of size 200 changes $G$ from a distribution in which each of the poor have $\$ X$ to a distribution in which each of the poor each have $\$ X+\$ 0.01$.

Finally, this modeling framework is consistent with our finding of strong and persistent individual differences. Individuals with a higher value of $\varphi_{i}$ will always behave more prosocially than individuals with lower values. The different conditions in our experiment affect how a prosocial action affects the subutility function $v$, but the benefits of acting prosocially will always be stronger for higher- $\varphi$ individuals.

Not all special cases of the general framework in (1) are consistent with our results. As shown in Appendix B, the Fehr and Schmidt (1999) model features an increasing function $\sigma(n)$, which implies that individuals would be more likely to vote on redistribution in large groups than in small groups, and that individuals would be more likely to vote for redistribution than give in the giving to one partner condition. As observed in Section 2.2, the Fehr and Schmidt (1999) model is also inconsistent with the fact that only 11.5 percent of poor participants wanted to decrease the payoffs of rich participants at no cost to themselves. This inconsitency arises under the standard assumption that $\alpha \geq \beta$; i.e, that people are more averse to being behind other than they are to being ahead of others. We show in Appendix B that the Fehr and Schmidt (1999) model implies that rich players would be less likely to vote for redistribution than poor players are to vote for reducing the payoffs of rich players. This is not the behavior that our participants exhibit.

Some popular models, such as Bolton and Ockenfels (2000), are not special cases of (1) and are also not consistent with our result of large differences between giving to many and voting on redistribution. As we show in Appendix B, the Bolton and Ockenfels (2000) model counterfactually predicts that there should be no difference in the propensity to give in these two conditions.

The strong preferences for redistribution and a general reluctance to destroy other players' payoffs is well-captured by the special case proposed in equation (2). This particular formulation generalizes the preferences proposed by and validated in Andreoni and Miller (2002) and Fisman et al. (2007) among others, while also being consistent with all of the results of our experiment.

Finally, we note that our formalization of group size effects offers a potential mechanism for the identifiable victim effect (Jenni and Loewenstein, 1997; Butts et al., 2019; Alós-Ferrer et al., 2021). 
This phenomena, which is occasionally also referred to as compassion fading or psychic numbing, is the finding that people are more likely to give to a single "identifiable" individual rather than to a large group (see also Fetherstonhaugh et al. 1997; Slovic 2007). This is predicted by our model under the assumption that, as in our giving to one partner frame, the identifiable victim effect operates by reducing the perceived group size.

\section{Conclusion}

This paper shows that many people have a strong preference for group-wide redistribution from rich to poor in both small and large groups, but a much weaker preference for individual giving in large groups. Preferences for voluntary giving match preferences for redistribution only in very small groups. These results are inconsistent with several prominent models of social preferences, but we provide a general theoretical framework that is consistent with our results. This general framework can aid future investigations of the types of redistributive mechanisms that can help

people implement their taste for redistribution in situations where the desire for voluntary giving is too weak to achieve the equitable outcomes that many desire. 


\section{References}

Alós-Ferrer, C., García-Segarra, J., and Ritschel, A. (2021). Generous with individuals and selfish to the masses. Nature Human Behaviour, pages 1-9.

Andreoni, J. (1990). Impure altruism and donations to public goods: A theory of warm-glow giving. The economic journal, 100(401):464-477.

Andreoni, J. (1993). An experimental test of the public goods crowding-out hypothesis. American Economic Review, 83(5):1317-1327.

Andreoni, J. (1995). Warm-glow versus cold-prickle: The effects of positive and negative framing on cooperation in experiments. Quarterly Journal of Economics, 110(1):1-21.

Andreoni, J. (2007). Giving gifts to groups: How altruism depends on the number of recipients. Journal of public Economics, 91(9):1731-1749.

Andreoni, J. and Miller, J. (2002). Giving according to garp: An experimental test of the consistency of preferences for altruism. Econometrica, 70(2):737-753.

Bolton, G. E. and Ockenfels, A. (2000). Erc: A theory of equity, reciprocity, and competition. American economic review, 90(1):166-193.

Brandts, J. and Charness, G. (2011). The strategy versus the direct-response method: a first survey of experimental comparisons. Experimental Economics, 14(3):375-398.

Butts, M. M., Lunt, D. C., Freling, T. L., and Gabriel, A. S. (2019). Helping one or helping many? a theoretical integration and meta-analytic review of the compassion fade literature. Organizational Behavior and Human Decision Processes, 151:16-33.

Carpenter, J. P. (2007). Punishing free-riders: How group size affects mutual monitoring and the provision of public goods. Games and Economic Behavior, 60(1):31-51.

Charite, J., Fisman, R., Kuziemko, I., and Zhang, K. (2022). Reference points and redistributive preferences: Experimental evidence. working paper.

Charness, G. and Rabin, M. (2002). Understanding social preferences with simple tests. The quarterly journal of economics, 117(3):817-869.

Diederich, J., Goeschl, T., and Waichman, I. (2016). Group size and the (in) efficiency of pure public good provision. European Economic Review, 85:272-287.

Durante, R., Putterman, L., and van der Weele, J. (2014). Preferences for redisribution and perception of fairness: An experimental study. Journal of the European Economic Association, 12(4):1059-1086. 
Fehr, E. and Schmidt, K. M. (1999). A theory of fairness, competition, and cooperation. The quarterly journal of economics, 114(3):817-868.

Fetherstonhaugh, D., Slovic, P., Johnson, S., and Friedrich, J. (1997). Insensitivity to the value of human life: A study of psychophysical numbing. Journal of Risk and uncertainty, 14(3):283-300.

Fisman, R., Jakiela, P., Kariv, S., and Markovits, D. (2015). The distributional preferences of an elite. Science, 349(6254):aab0096.

Fisman, R., Kariv, S., and Markovits, D. (2007). Individual preferences for giving. American Economic Review, 97(5):1858-1876.

Fisman, R., Kuziemko, I., and Vannutelli, S. (2021). Distributional preferences in larger groups: Keeping up with the joneses and keeping track of the tails. Journal of the European Economic Association, 19(2):1407-1438.

Isaac, R. M. and Walker, J. M. (1988). Group size effects in public goods provision: The voluntary contributions mechanism. The Quarterly Journal of Economics, 103(1):179-199.

Isaac, R. M., Walker, J. M., and Williams, A. W. (1994). Group size and the voluntary provision of public goods: Experimental evidence utilizing large groups. Journal of public Economics, $54(1): 1-36$.

Jenni, K. E. and Loewenstein, G. (1997). Explaining the identifiable victim effect. Journal of Risk and Uncertainty, 14:235-257.

Kuziemko, I., Buell, R. W., Reich, T., and Norton, M. I. (2014). Last-place aversion: Evidence and redistributive implications. The Quarterly Journal of Economics, 129(1):105-149.

O'Brien, S. (2021). Many wealthy households support higher taxes on the rich and corporate america, CNBC millionaire survey shows. https://www.cnbc.com/2021/06/09/ many-millionaires-support-higher-taxes-on-rich-and-corporate-america.html. Accessed: 2022-4-4.

Rabin, M. (1995). Moral preferneces, moral constraints, and self-serving biases. working paper.

Schumacher, H., Kesternich, I., Kosfeld, M., and Winter, J. (2017). One, two, many-insensitivity to group size in games with concentrated benefits and dispersed costs. The Review of Economic Studies, 84(3):1346-1377.

Selten, R. (1967). Die strategiemethode zur erforschung des eingeschränkt rationalen verhaltens im rahmen eines oligopolexperimentes. Beiträge Zur Experimentellen Wirtschaftsforschung, pages $136-168$.

Slovic, P. (2007). "If I look at the mass I will never act": Psychic numbing and genocide. Judgment and Decision Making, 2(2):79-95. 
Weimann, J., Brosig-Koch, J., Heinrich, T., Hennig-Schmidt, H., and Keser, C. (2019). Public good provision by large groups-the logic of collective action revisited. European Economic Review, 118:348-363. 
Figure 1: Summary of Experimental Decisions

Scenario

Giving to Many

Giving to One /

\section{Last Sentence}

Do you want to spend $X$ of your 350 cents to increase each B-player's payoff by $Y$ cents?

Do you want to spend $X$ of your 350 cents to increase a random one of the B-player's payoff by 100 cents?

Do you want to spend $X$ of your 350 cents to increase your paired B-player's payoff by 100 cents?

\section{Voting on Redistribution}

Do you want to vote for or against each of the B-players getting 100 cents at a cost of $X$ to each of the A-players?

Notes: This figure summarizes the experimental conditions and shows the last sentence participants are asked before making a decision in each of the scenarios. Each "Scenario," or decision set, involves three decisions that differ in the price of giving, $X \in\{80,100,120\}$. $Y$ varies with group size: $Y=50$ in small groups, $Y=1$ in large groups.

Figure 2: Prosocial choice by scenario and group size

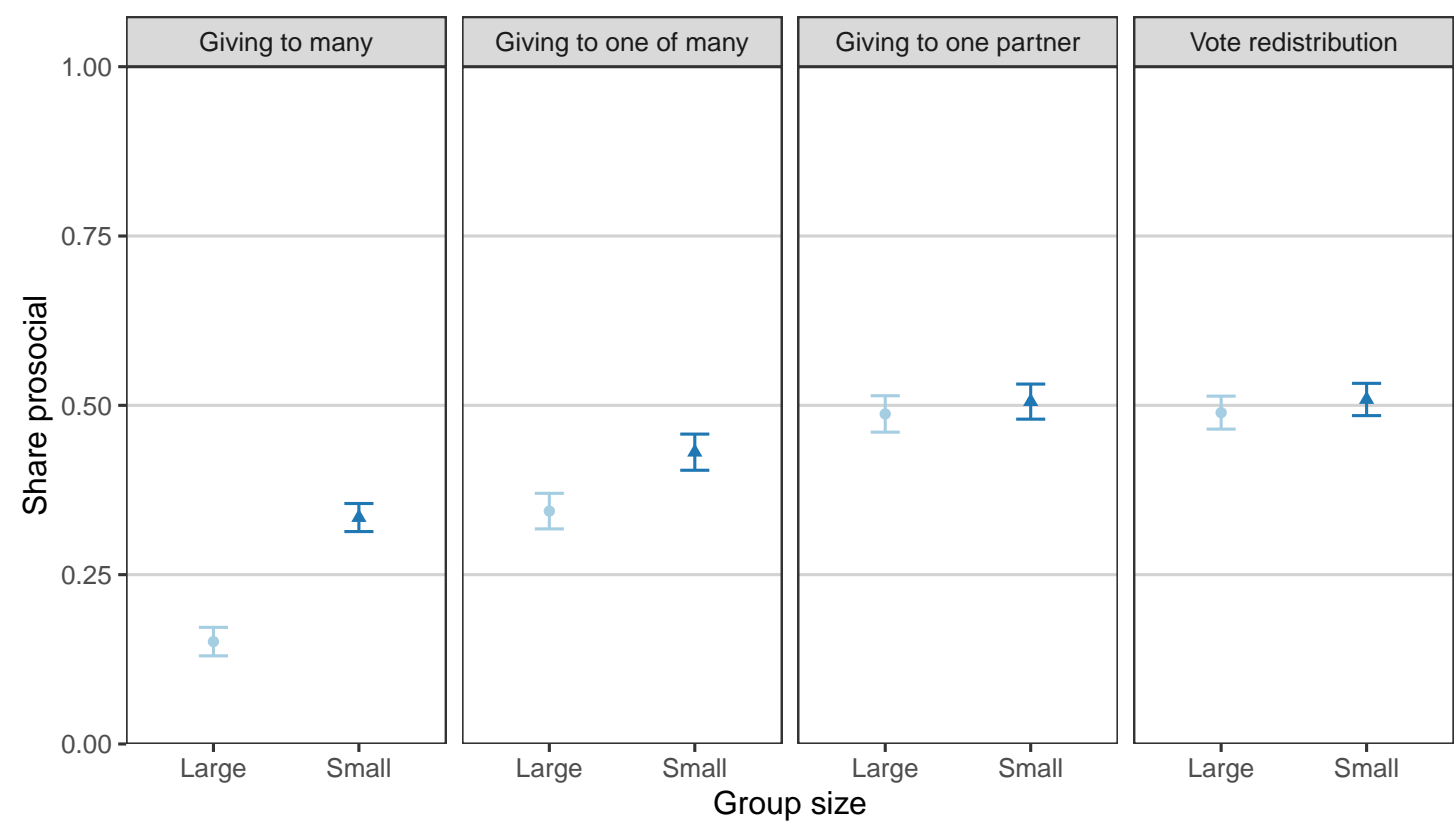

Notes: This figure summarizes the share of choices in favor of giving or redistribution, by the type of decision and group size. The averages pool across the three different prices of giving/redistributing within each decision set. The point estimates are produced by running a regression of acting prosocially on 8 dummy variables corresponding to each of the 8 pairs of conditions in the figure, which result from crossing four decision sets with two possible group sizes. Standard errors clustered at the participant level and error bars represent $95 \%$ confidence intervals. 
Figure 3: Prosocial choice by scenario, group size, and price

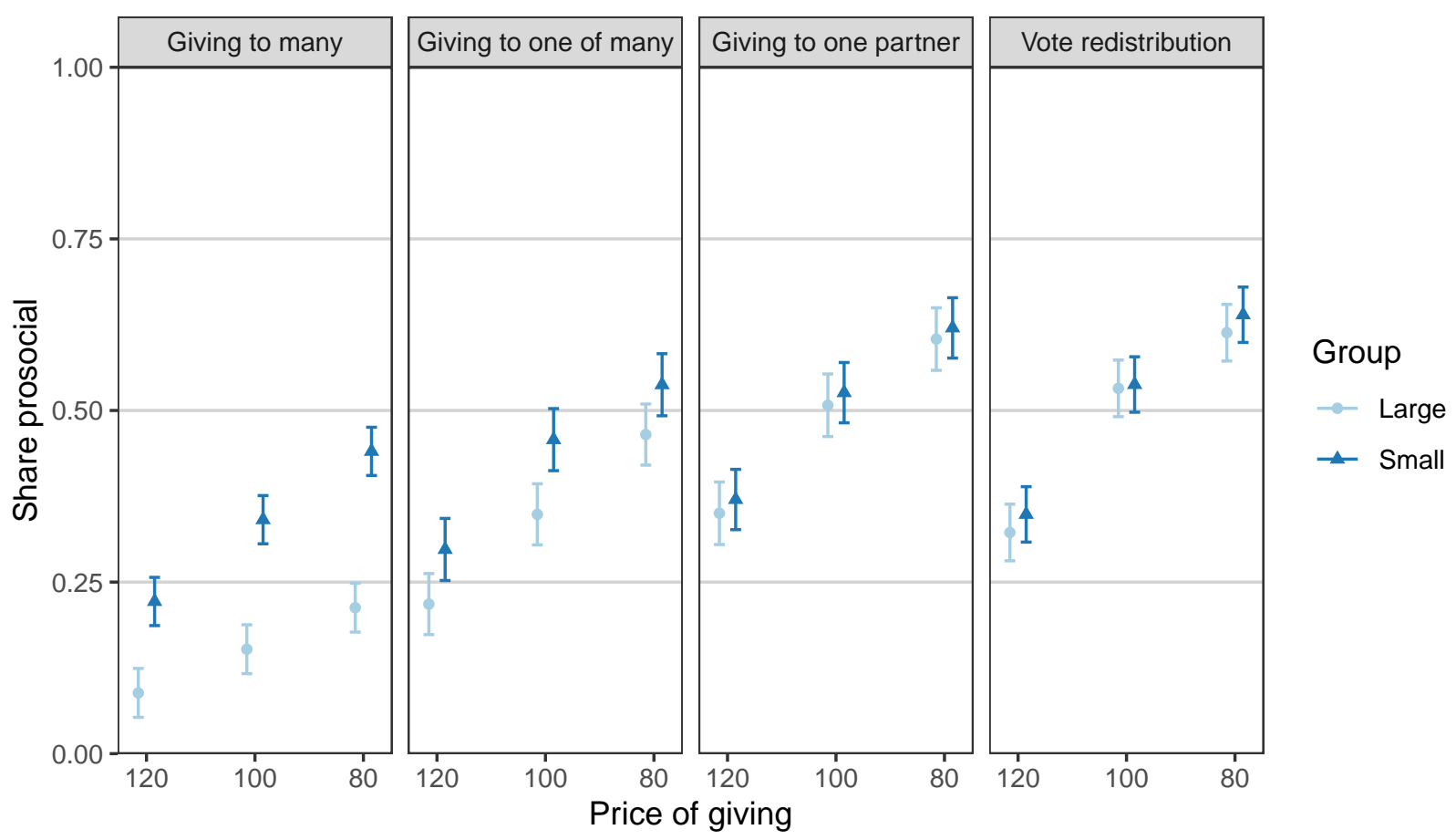

Notes: This figure summarizes the share of choices in favor of giving or redistribution, by the type of decision, group size, and price of giving. The point estimates are produced by running a regression of acting prosocially on 24 dummy variables corresponding to each of the 24 conditions in the figure, which result from crossing four decision sets with two possible group sizes and three prices. Standard errors are clustered at the participant level and error bars represent $95 \%$ confidence intervals. 
Table 1: Likelihood of prosocial choice by condition

\begin{tabular}{|c|c|c|c|c|c|c|}
\hline & $(1)$ & $(2)$ & $(3)$ & (4) & $(5)$ & (6) \\
\hline Giving to many & $\begin{array}{c}-0.174^{* * *} \\
(0.016)\end{array}$ & $\begin{array}{c}-0.165^{* *} \\
(0.021)\end{array}$ & $\begin{array}{c}-0.115^{* * *} \\
(0.008)\end{array}$ & $\begin{array}{c}-0.204^{* *} \\
(0.023)\end{array}$ & $\begin{array}{c}-0.153^{* * *} \\
(0.005)\end{array}$ & $\begin{array}{c}-0.165^{* *} \\
(0.021)\end{array}$ \\
\hline Giving to one & $\begin{array}{c}-0.078^{* * * *} \\
(0.018)\end{array}$ & $\begin{array}{c}-0.059^{*} \\
(0.015)\end{array}$ & $\begin{array}{l}-0.071 \\
(0.030)\end{array}$ & $\begin{array}{c}-0.050^{* *} \\
(0.010)\end{array}$ & $\begin{array}{l}-0.069 \\
(0.027)\end{array}$ & $\begin{array}{c}-0.060^{* *} \\
(0.014)\end{array}$ \\
\hline Giving to one $\mathrm{x}$ Partner & $\begin{array}{c}0.075^{* * *} \\
(0.019)\end{array}$ & $\begin{array}{c}0.068^{* *} \\
(0.009)\end{array}$ & $\begin{array}{l}0.055^{*} \\
(0.015)\end{array}$ & $\begin{array}{c}0.071^{* * *} \\
(0.007)\end{array}$ & $\begin{array}{c}0.128^{* *} \\
(0.021)\end{array}$ & $\begin{array}{c}0.070^{* *} \\
(0.009)\end{array}$ \\
\hline Large $\mathrm{x}$ Vote redistribution & $\begin{array}{l}-0.019 \\
(0.017)\end{array}$ & $\begin{array}{l}-0.019 \\
(0.007)\end{array}$ & $\begin{array}{c}-0.055^{*} \\
(0.016)\end{array}$ & $\begin{array}{l}-0.019 \\
(0.007)\end{array}$ & $\begin{array}{l}-0.041 \\
(0.029)\end{array}$ & $\begin{array}{c}-0.021^{*} \\
(0.006)\end{array}$ \\
\hline Large $x$ Giving to many & $\begin{array}{c}-0.357^{* * *} \\
(0.016)\end{array}$ & $\begin{array}{c}-0.347^{* *} \\
(0.048)\end{array}$ & $\begin{array}{c}-0.331^{* *} \\
(0.042)\end{array}$ & $\begin{array}{c}-0.445^{* *} \\
(0.058)\end{array}$ & $\begin{array}{c}-0.406^{* *} \\
(0.044)\end{array}$ & $\begin{array}{c}-0.349^{* *} \\
(0.049)\end{array}$ \\
\hline Large $x$ Giving to one & $\begin{array}{c}-0.165^{* * *} \\
(0.018)\end{array}$ & $\begin{array}{c}-0.145^{* *} \\
(0.017)\end{array}$ & $\begin{array}{c}-0.157^{* * *} \\
(0.012)\end{array}$ & $\begin{array}{c}-0.191^{* *} \\
(0.023)\end{array}$ & $\begin{array}{c}-0.167^{* * *} \\
(0.008)\end{array}$ & $\begin{array}{c}-0.146^{* *} \\
(0.017)\end{array}$ \\
\hline Large $\mathrm{x}$ Giving to one $\mathrm{x}$ Partner & $\begin{array}{c}0.143^{* * * *} \\
(0.019)\end{array}$ & $\begin{array}{c}0.136^{* * *} \\
(0.012)\end{array}$ & $\begin{array}{c}0.134^{* * * *} \\
(0.002)\end{array}$ & $\begin{array}{c}0.188^{* * * *} \\
(0.018)\end{array}$ & $\begin{array}{c}0.155^{* * * *} \\
(0.003)\end{array}$ & $\begin{array}{c}0.134^{* * *} \\
(0.013)\end{array}$ \\
\hline $\mathrm{N}$ & 11763 & 11763 & 3921 & 8640 & 2880 & 11763 \\
\hline Participants & 1307 & 1307 & 1307 & 960 & 960 & 1307 \\
\hline Sample & All & All & 1st round & DG givers & $\begin{array}{l}\text { 1st round, } \\
\text { DG givers }\end{array}$ & All \\
\hline Price fixed effects & & Yes & Yes & Yes & Yes & Yes \\
\hline Order fixed effects & & Yes & NA & Yes & NA & Yes \\
\hline Demographics & & & & & & Yes \\
\hline
\end{tabular}

Notes: This table shows the differences in likelihood of making a prosocial decision by experimental condition. The omitted category is voting for redistribution in the small group. The baseline specification in column (1) regresses prosocial choice on dummies for each of "giving to one", "voting for redistribution", and "giving to many" interacted with a dummy for "Large" group; also, "giving to one" is interacted with a dummy that equals 1 for "partner" and 0 for "one of many". Therefore, rows 3 and 7 show the effects of giving to one partner relative to giving to one of many. The baseline sample are all participants who passed a comprehension quiz and did not violate monotonicity in their choices. Column (1) is the entire sample with no controls. Column (2)-(6) add price and order of scenarios fixed effects. Column (3) restricts the sample to the first set of 3 decisions only. Column (4) restricts the sample to participants who later gave a positive amount in a dictator game. Column (5) is first set of 3 choices of dictator-game givers. Column (6) is adds demographic controls to the specification in column (2). Standard errors are clustered at the participant level. ${ }^{* * *} \mathrm{p}<.01,{ }^{* *} \mathrm{p}<0.05,{ }^{*} \mathrm{p}<.10$. 
Table 2: Within-individual correlation in prosocial choices between scenarios

\begin{tabular}{llll}
\hline & Giving to one of many & Giving to one partner & Vote redistribution \\
\hline Giving to many & 0.539 & 0.55 & 0.513 \\
Giving to one of many & & & 0.762 \\
Giving to one partner & & 0.882 \\
\hline
\end{tabular}

Notes: This table reports within-individual pairwise correlations, between the prosocial choices in the different types of decisions. For each participant, we first aggregate prosocial choice at the type of decision level (out of 3 possible giving decisions), and then compute the pairwise correlations. For each person $i$ and condition $k$, we compute the fraction $f_{i k}$ of the three decisions in which the person acted to increase the resources of the poor players. 
Online Appendix, Not For Publication

\section{The Impact of Group Size on Demand for Redistribution and Giving}

Johanna Mollerstrom, Avner Strulov-Shlain, Dmitry Taubinsky

\section{A Supplementary Empirical Results}

\section{A.1 Replication Using the Full 1600-Person Sample}

Figure A1: Prosocial choice by scenario and group size

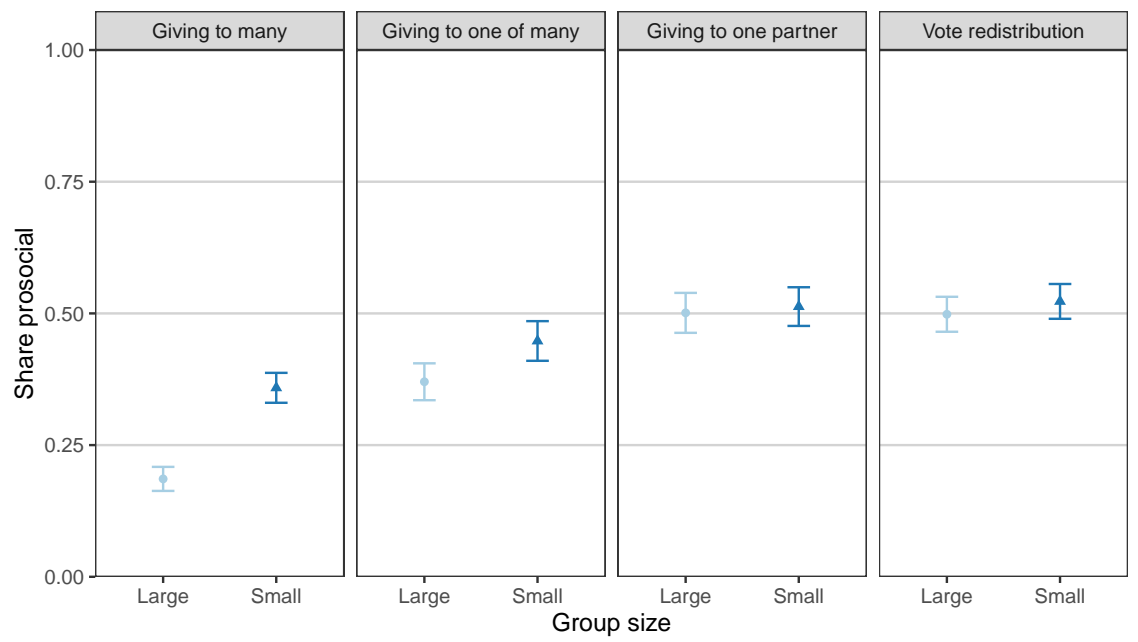

Notes: This figure replicates Figure 2, with the underlying sample being the full 1600-person sample. 
Figure A2: Prosocial choice by scenario, group size, and price

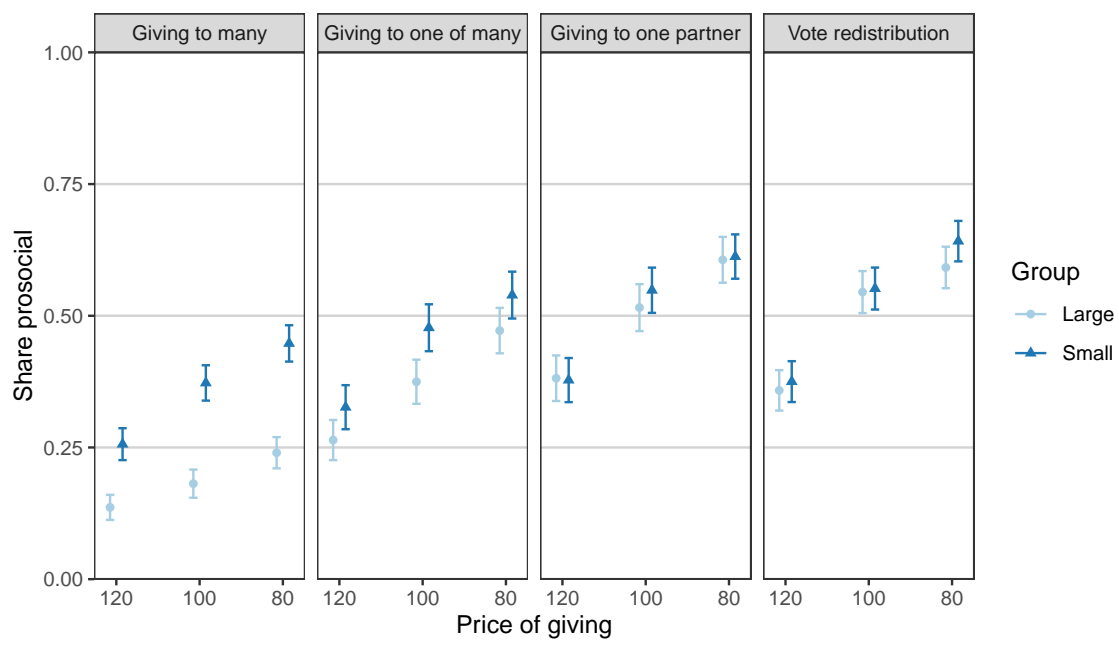

Notes: This figure replicates Figure 3, with the underlying sample being the full 1600-person sample. 
Table A1: Prosocial choices, alternative sample (Full)

\begin{tabular}{|c|c|c|c|c|c|c|}
\hline & $(1)$ & $(2)$ & $(3)$ & $(4)$ & $(5)$ & (6) \\
\hline Giving to many & $\begin{array}{c}-0.164^{* * *} \\
(0.015)\end{array}$ & $\begin{array}{c}-0.155^{* * *} \\
(0.014)\end{array}$ & $\begin{array}{c}-0.088^{* *} \\
(0.043)\end{array}$ & $\begin{array}{c}-0.183^{* * *} \\
(0.017)\end{array}$ & $\begin{array}{c}-0.106^{* *} \\
(0.046)\end{array}$ & $\begin{array}{c}-0.156^{* * *} \\
(0.014)\end{array}$ \\
\hline Giving to one & $\begin{array}{c}-0.075^{* * *} \\
(0.019)\end{array}$ & $\begin{array}{c}-0.059^{* * *} \\
(0.016)\end{array}$ & $\begin{array}{c}-0.078^{*} \\
(0.043)\end{array}$ & $\begin{array}{c}-0.048^{* * *} \\
(0.018)\end{array}$ & $\begin{array}{c}-0.077^{*} \\
(0.046)\end{array}$ & $\begin{array}{c}-0.061^{* * *} \\
(0.015)\end{array}$ \\
\hline Giving to one $\mathrm{x}$ Partner & $\begin{array}{c}0.065^{* * *} \\
(0.022)\end{array}$ & $\begin{array}{c}0.061^{* * *} \\
(0.017)\end{array}$ & $\begin{array}{c}0.047 \\
(0.044)\end{array}$ & $\begin{array}{c}0.063^{* * *} \\
(0.020)\end{array}$ & $\begin{array}{c}0.122^{* * *} \\
(0.047)\end{array}$ & $\begin{array}{c}0.064^{* * *} \\
(0.017)\end{array}$ \\
\hline Large $\mathrm{x}$ Vote redistribution & $\begin{array}{l}-0.024 \\
(0.024)\end{array}$ & $\begin{array}{c}-0.024 \\
(0.024)\end{array}$ & $\begin{array}{l}-0.063 \\
(0.040)\end{array}$ & $\begin{array}{l}-0.026 \\
(0.025)\end{array}$ & $\begin{array}{l}-0.047 \\
(0.043)\end{array}$ & $\begin{array}{c}-0.022 \\
(0.023)\end{array}$ \\
\hline Large $\mathrm{x}$ Giving to many & $\begin{array}{c}-0.337^{* * *} \\
(0.020)\end{array}$ & $\begin{array}{c}-0.328^{* * *} \\
(0.020)\end{array}$ & $\begin{array}{c}-0.305^{* * *} \\
(0.038)\end{array}$ & $\begin{array}{c}-0.404^{* * *} \\
(0.022)\end{array}$ & $\begin{array}{c}-0.363^{* * *} \\
(0.043)\end{array}$ & $\begin{array}{c}-0.324^{* * *} \\
(0.020)\end{array}$ \\
\hline Large $\mathrm{x}$ Giving to one & $\begin{array}{c}-0.153^{* * *} \\
(0.025)\end{array}$ & $\begin{array}{c}-0.136^{* * *} \\
(0.023)\end{array}$ & $\begin{array}{c}-0.155^{* * *} \\
(0.041)\end{array}$ & $\begin{array}{c}-0.168^{* * *} \\
(0.026)\end{array}$ & $\begin{array}{c}-0.156^{* * *} \\
(0.045)\end{array}$ & $\begin{array}{c}-0.131^{* * *} \\
(0.023)\end{array}$ \\
\hline Large $\mathrm{x}$ Giving to one $\mathrm{x}$ Partner & $\begin{array}{c}0.131^{* * *} \\
(0.022)\end{array}$ & $\begin{array}{c}0.128^{* * *} \\
(0.020)\end{array}$ & $\begin{array}{c}0.141^{* * * *} \\
(0.043)\end{array}$ & $\begin{array}{c}0.164^{* * *} \\
(0.024)\end{array}$ & $\begin{array}{c}0.152^{* * *} \\
(0.047)\end{array}$ & $\begin{array}{c}0.125^{* * *} \\
(0.020)\end{array}$ \\
\hline $\mathrm{N}$ & 14400 & 14400 & 4800 & 10971 & 3657 & 14400 \\
\hline Participants & 1600 & 1600 & 1600 & 1219 & 1219 & 1600 \\
\hline Sample & All & All & 1 st round & DG givers & $\begin{array}{l}\text { 1st round, } \\
\text { DG givers }\end{array}$ & All \\
\hline Price fixed effects & & Yes & Yes & Yes & Yes & Yes \\
\hline Order fixed effects & & Yes & NA & Yes & NA & Yes \\
\hline Demographics & & & & & & Yes \\
\hline
\end{tabular}

Notes: This table replicates Table 1 , but includes all participants who completed the experiment. $* * * \mathrm{p}<.01$, ** $\mathrm{p}<0.05,{ }^{*} \mathrm{p}<.10$. 


\section{A.2 Replication on Sample Without the Monotonicity Restriction}

Figure A3: Prosocial choice by Scenario and Group size

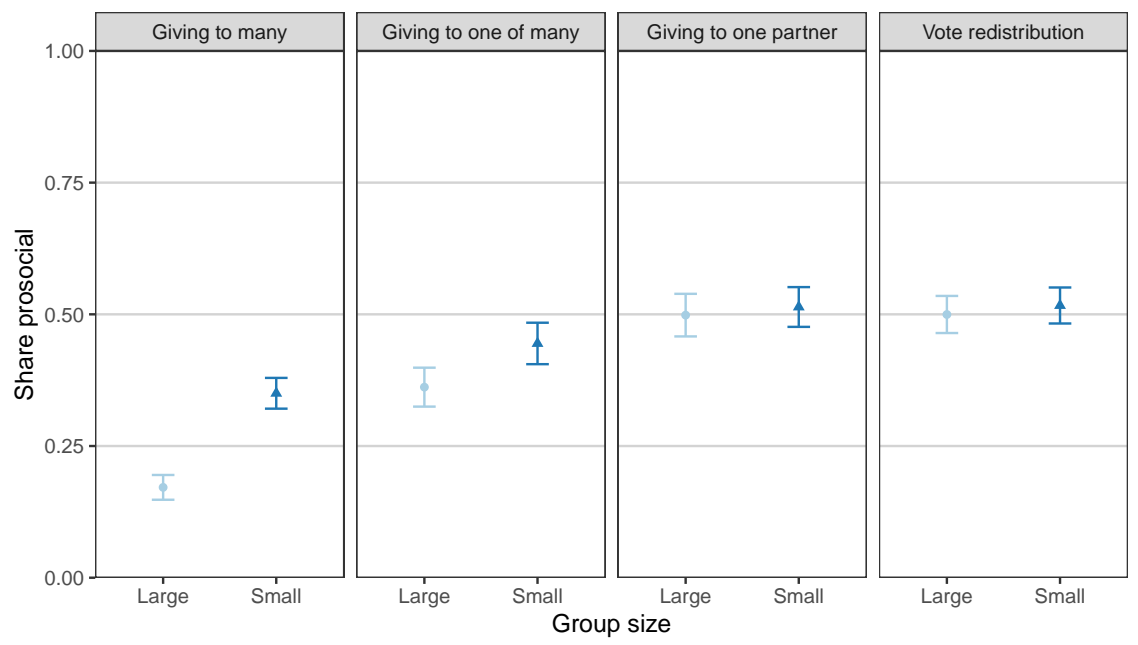

Notes: This figure replicates Figure 2, with the underlying sample being the 1480 participants who passed the comprehension quiz.

Figure A4: Prosocial choice by scenario, group size, and price

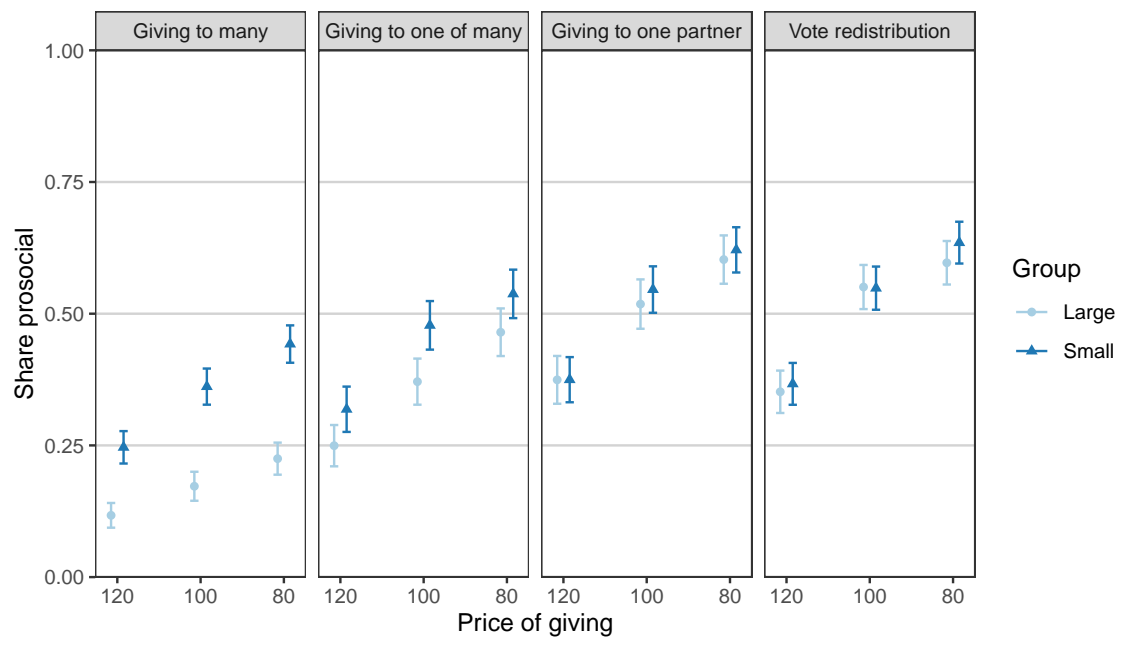

Notes: This figure replicates Figure 3, with the underlying sample being the 1480 participants who passed the comprehension quiz. 
Table A2: Prosocial choices, alternative sample (Passed Quiz)

\begin{tabular}{|c|c|c|c|c|c|c|}
\hline & $(1)$ & $(2)$ & $(3)$ & $(4)$ & $(5)$ & (6) \\
\hline Giving to many & $\begin{array}{c}-0.167^{* * *} \\
(0.015)\end{array}$ & $\begin{array}{c}-0.158^{* * *} \\
(0.014)\end{array}$ & $\begin{array}{c}-0.093^{* *} \\
(0.044)\end{array}$ & $\begin{array}{c}-0.190^{* * *} \\
(0.017)\end{array}$ & $\begin{array}{c}-0.119^{* *} \\
(0.048)\end{array}$ & $\begin{array}{c}-0.159^{* * *} \\
(0.014)\end{array}$ \\
\hline Giving to one & $\begin{array}{c}-0.072^{* * *} \\
(0.020)\end{array}$ & $\begin{array}{c}-0.058^{* * *} \\
(0.016)\end{array}$ & $\begin{array}{c}-0.075^{*} \\
(0.045)\end{array}$ & $\begin{array}{c}-0.048^{* *} \\
(0.019)\end{array}$ & $\begin{array}{l}-0.076 \\
(0.048)\end{array}$ & $\begin{array}{c}-0.060^{* * *} \\
(0.016)\end{array}$ \\
\hline Giving to one $\mathrm{x}$ Partner & $\begin{array}{c}0.069^{* * *} \\
(0.022)\end{array}$ & $\begin{array}{c}0.067^{* * *} \\
(0.017)\end{array}$ & $\begin{array}{c}0.051 \\
(0.046)\end{array}$ & $\begin{array}{c}0.068^{* * *} * \\
(0.020)\end{array}$ & $\begin{array}{c}0.125^{* * *} \\
(0.048)\end{array}$ & $\begin{array}{c}0.071^{* * *} \\
(0.017)\end{array}$ \\
\hline Large $\mathrm{x}$ Vote redistribution & $\begin{array}{l}-0.017 \\
(0.025)\end{array}$ & $\begin{array}{l}-0.017 \\
(0.025)\end{array}$ & $\begin{array}{l}-0.056 \\
(0.042)\end{array}$ & $\begin{array}{l}-0.017 \\
(0.026)\end{array}$ & $\begin{array}{l}-0.047 \\
(0.045)\end{array}$ & $\begin{array}{c}-0.014 \\
(0.024)\end{array}$ \\
\hline Large $\mathrm{x}$ Giving to many & $\begin{array}{c}-0.345^{* * *} \\
(0.021)\end{array}$ & $\begin{array}{c}-0.337^{* * *} \\
(0.020)\end{array}$ & $\begin{array}{c}-0.316^{* * *} \\
(0.040)\end{array}$ & $\begin{array}{c}-0.420^{* * *} \\
(0.023)\end{array}$ & $\begin{array}{c}-0.380^{* * *} \\
(0.045)\end{array}$ & $\begin{array}{c}-0.333^{* * *} \\
(0.020)\end{array}$ \\
\hline Large $\mathrm{x}$ Giving to one & $\begin{array}{c}-0.155^{* * *} \\
(0.026)\end{array}$ & $\begin{array}{c}-0.141^{* * *} \\
(0.024)\end{array}$ & $\begin{array}{c}-0.149^{* * *} \\
(0.043)\end{array}$ & $\begin{array}{c}-0.175^{* * *} \\
(0.027)\end{array}$ & $\begin{array}{c}-0.149^{* * *} \\
(0.047)\end{array}$ & $\begin{array}{c}-0.135^{* * *} \\
(0.024)\end{array}$ \\
\hline Large $\mathrm{x}$ Giving to one $\mathrm{x}$ Partner & $\begin{array}{c}0.137^{* * * *} \\
(0.024)\end{array}$ & $\begin{array}{c}0.135^{* * *} \\
(0.022)\end{array}$ & $\begin{array}{c}0.133^{* * * *} \\
(0.047)\end{array}$ & $\begin{array}{c}0.176^{* * *} \\
(0.025)\end{array}$ & $\begin{array}{c}0.147^{* * *} * \\
(0.052)\end{array}$ & $\begin{array}{c}0.131^{* * *} \\
(0.021)\end{array}$ \\
\hline $\mathrm{N}$ & 13320 & 13320 & 4440 & 10044 & 3348 & 13320 \\
\hline Participants & 1480 & 1480 & 1480 & 1116 & 1116 & 1480 \\
\hline Sample & All & All & 1 st round & DG givers & $\begin{array}{l}\text { 1st round, } \\
\text { DG givers }\end{array}$ & All \\
\hline Price fixed effects & & Yes & Yes & Yes & Yes & Yes \\
\hline Order fixed effects & & Yes & NA & Yes & NA & Yes \\
\hline Demographics & & & & & & Yes \\
\hline
\end{tabular}

Notes: This table replicates Table 1, but includes all participants who completed the experiment and passed a comprehension quiz. ${ }^{* * *} \mathrm{p}<.01,{ }^{* *} \mathrm{p}<0.05,{ }^{*} \mathrm{p}<.10$. 


\section{A.3 Histogram of Prosocial Choices}

Figure A5: Histogram of total prosocial choices

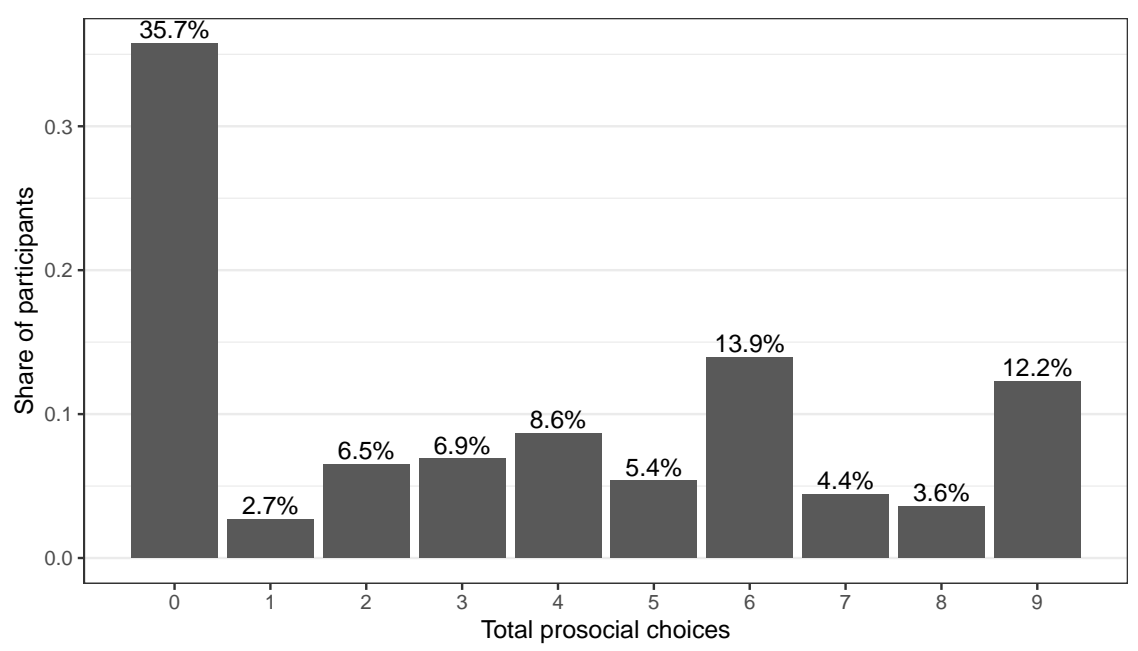

Notes: This figure shows the distribution of participants by their total number of prosocial choices. The horizontal axis is the total number of prosocial choices and the vertical axis is the share of participants. Numbers above the bars show their height translated to percent.

\section{A.4 Distribution of Amount Given in Dictator Game}

Figure A6: CDF of amount given in Dictator Game

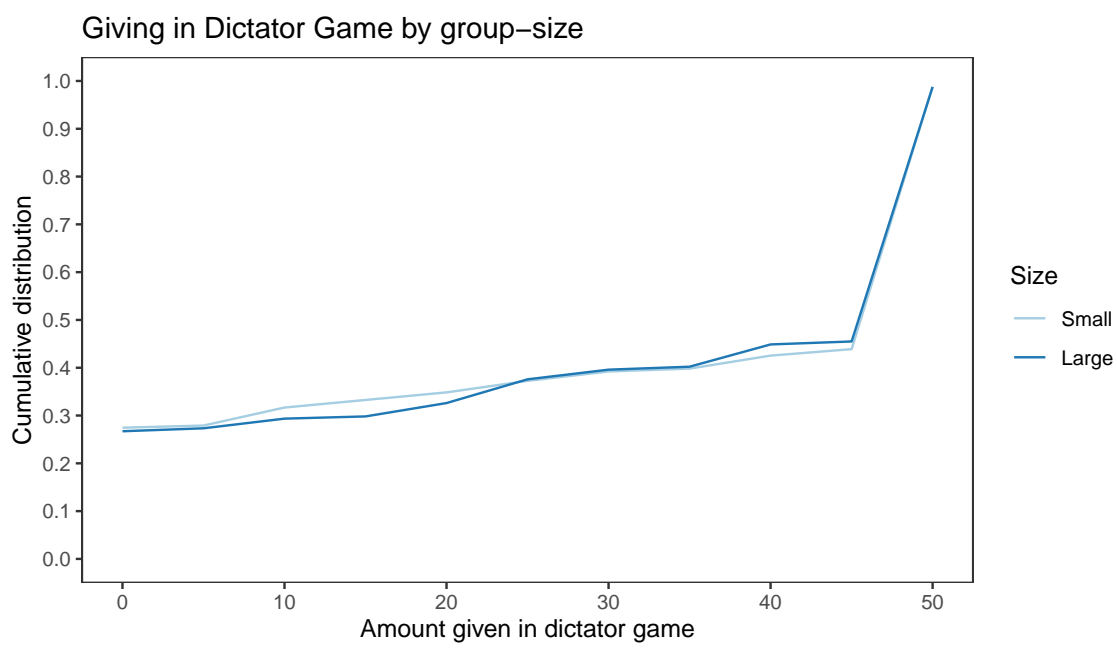

Notes: This figure shows the cumulative distribution of amount given in a "dictator game" out of 100 cents. The dark curve represents players who were assigned to the large group (light $=$ small). 


\section{A.5 Balance Table}

Table A3: Balance Table

\begin{tabular}{|c|c|c|c|c|c|c|c|}
\hline \multirow{2}{*}{$\begin{array}{l}\text { Group } \\
\text { Variable }\end{array}$} & \multicolumn{3}{|c|}{ Large } & \multicolumn{3}{|c|}{ Small } & \multirow[b]{2}{*}{ Test } \\
\hline & $\mathrm{N}$ & Mean & $\mathrm{SD}$ & $\mathrm{N}$ & Mean & $\mathrm{SD}$ & \\
\hline Social issue scale & 644 & 3.957 & 2.372 & 663 & 4.018 & 2.347 & $p=0.637$ \\
\hline Economic issue scale & 644 & 4.679 & 2.438 & 663 & 4.64 & 2.461 & $p=0.773$ \\
\hline Political party & 644 & & & 663 & & & $p=0.972$ \\
\hline ... Democrat & 283 & $43.9 \%$ & & 287 & $43.3 \%$ & & \\
\hline ... Independent & 217 & $33.7 \%$ & & 226 & $34.1 \%$ & & \\
\hline ... Republican & 144 & $22.4 \%$ & & 150 & $22.6 \%$ & & \\
\hline Affiliation with political party & 644 & 5.871 & 2.262 & 663 & 5.894 & 2.338 & $p=0.855$ \\
\hline View on government's role on redistribution & 644 & 6.297 & 2.855 & 663 & 6.469 & 2.774 & $p=0.268$ \\
\hline View on redistribution of resources & 644 & 5.997 & 2.892 & 663 & 6.092 & 2.895 & $p=0.553$ \\
\hline Belief in institutional responsible for redistribution & 644 & 5.351 & 2.464 & 663 & 5.584 & 2.337 & $p=0.080^{*}$ \\
\hline The role of luck or effect in economic success & 644 & 6.228 & 1.86 & 663 & 6.225 & 1.806 & $p=0.972$ \\
\hline Involvement with other studies involving division of Money & 644 & 2.648 & 0.949 & 663 & 2.683 & 0.958 & $p=0.498$ \\
\hline Age & 644 & 36.149 & 11.763 & 663 & 35.287 & 11.27 & $p=0.176$ \\
\hline Gender & 644 & & & 663 & & & $p=0.794$ \\
\hline ... Female & 312 & $48.4 \%$ & & 316 & $47.7 \%$ & & \\
\hline ... Male & 330 & $51.2 \%$ & & 346 & $52.2 \%$ & & \\
\hline ... I do not identify myself as male or female. & 2 & $0.3 \%$ & & 1 & $0.2 \%$ & & \\
\hline Ethnicity & 644 & & & 663 & & & $p=0.737$ \\
\hline ... Asian & 52 & $8.1 \%$ & & 44 & $6.6 \%$ & & \\
\hline ... Black & 35 & $5.4 \%$ & & 43 & $6.5 \%$ & & \\
\hline ... Hispanic-Latino & 36 & $5.6 \%$ & & 35 & $5.3 \%$ & & \\
\hline ... Native American & 3 & $0.5 \%$ & & 2 & $0.3 \%$ & & \\
\hline ... White & 505 & $78.4 \%$ & & 530 & $79.9 \%$ & & \\
\hline ... Other & 13 & $2 \%$ & & 9 & $1.4 \%$ & & \\
\hline Student & 644 & & & 663 & & & $p=0.726$ \\
\hline$\ldots 0$ & 552 & $85.7 \%$ & & 576 & $86.9 \%$ & & \\
\hline$\ldots 1$ & 90 & $14 \%$ & & 84 & $12.7 \%$ & & \\
\hline ... Not Answered & 2 & $0.3 \%$ & & 3 & $0.5 \%$ & & \\
\hline Married & 642 & 0.551 & 0.498 & 660 & 0.539 & 0.499 & $p=0.664$ \\
\hline Personal Income & 644 & & & 663 & & & $p=0.680$ \\
\hline$\ldots$ Less than $\$ 10,000$ & 141 & $21.9 \%$ & & 148 & $22.3 \%$ & & \\
\hline$\ldots \$ 10,000$ to $\$ 20,000$ & 107 & $16.6 \%$ & & 90 & $13.6 \%$ & & \\
\hline$\ldots \$ 20,000$ to $\$ 30,000$ & 94 & $14.6 \%$ & & 85 & $12.8 \%$ & & \\
\hline$\ldots \$ 30,000$ to $\$ 40,000$ & 86 & $13.4 \%$ & & 96 & $14.5 \%$ & & \\
\hline$\ldots \$ 40,000$ to $\$ 50,000$ & 55 & $8.5 \%$ & & 68 & $10.3 \%$ & & \\
\hline$\ldots \$ 50,000$ to $\$ 60,000$ & 49 & $7.6 \%$ & & 59 & $8.9 \%$ & & \\
\hline$\ldots \$ 60,000$ to $\$ 70,000$ & 36 & $5.6 \%$ & & 39 & $5.9 \%$ & & \\
\hline$\ldots \$ 70,000$ to $\$ 80,000$ & 32 & $5 \%$ & & 28 & $4.2 \%$ & & \\
\hline$\ldots \$ 80,000$ to $\$ 90,000$ & 21 & $3.3 \%$ & & 17 & $2.6 \%$ & & \\
\hline$\ldots \$ 90,000$ to $\$ 100,000$ & 5 & $0.8 \%$ & & 9 & $1.4 \%$ & & \\
\hline$\ldots$ Over $\$ 100,000$ & 18 & $2.8 \%$ & & 24 & $3.6 \%$ & & \\
\hline
\end{tabular}


Table A3: Balance Table (Continued)

\begin{tabular}{|c|c|c|c|c|c|c|c|}
\hline Group & & Large & & & Small & & \\
\hline Variable & $\mathrm{N}$ & Mean & $\mathrm{SD}$ & $\mathrm{N}$ & Mean & $\mathrm{SD}$ & Test \\
\hline Household Income & 644 & & & 663 & & & $p=0.906$ \\
\hline ... Less than $\$ 20,000$ & 60 & $9.3 \%$ & & 61 & $9.2 \%$ & & \\
\hline$\ldots \$ 20,000$ to $\$ 40,000$ & 120 & $18.6 \%$ & & 119 & $17.9 \%$ & & \\
\hline$\ldots \$ 40,000$ to $\$ 60,000$ & 129 & $20 \%$ & & 116 & $17.5 \%$ & & \\
\hline$\ldots \$ 60,000$ to $\$ 80,000$ & 106 & $16.5 \%$ & & 111 & $16.7 \%$ & & \\
\hline$\ldots \$ 80,000$ to $\$ 100,000$ & 60 & $9.3 \%$ & & 62 & $9.4 \%$ & & \\
\hline$\ldots \$ 100,000$ to $\$ 120,000$ & 42 & $6.5 \%$ & & 47 & $7.1 \%$ & & \\
\hline$\ldots \$ 120,000$ to $\$ 140,000$ & 25 & $3.9 \%$ & & 22 & $3.3 \%$ & & \\
\hline$\ldots \$ 140,000$ to $\$ 160,000$ & 13 & $2 \%$ & & 19 & $2.9 \%$ & & \\
\hline$\ldots \$ 160,000$ to $\$ 180,000$ & 8 & $1.2 \%$ & & 9 & $1.4 \%$ & & \\
\hline$\ldots \$ 180,000$ to $\$ 200,000$ & 2 & $0.3 \%$ & & 3 & $0.5 \%$ & & \\
\hline$\ldots$ Over $\$ 200,000$ & 10 & $1.6 \%$ & & 19 & $2.9 \%$ & & \\
\hline ... Not Applicable & 69 & $10.7 \%$ & & 75 & $11.3 \%$ & & \\
\hline Education & 644 & & & 663 & & & $p=0.917$ \\
\hline ... Less than a high school degree & 3 & $0.5 \%$ & & 1 & $0.2 \%$ & & \\
\hline ... High School Diploma & 95 & $14.8 \%$ & & 101 & $15.2 \%$ & & \\
\hline ... Attended College & 179 & $27.8 \%$ & & 177 & $26.7 \%$ & & \\
\hline ... Bachelor's Degree & 263 & $40.8 \%$ & & 274 & $41.3 \%$ & & \\
\hline ... Graduate Degree & 79 & $12.3 \%$ & & 86 & $13 \%$ & & \\
\hline ... Vocational Training & 25 & $3.9 \%$ & & 24 & $3.6 \%$ & & \\
\hline Major & 644 & & & 663 & & & $p=0.027^{* *}$ \\
\hline ... Business / MBA & 81 & $12.6 \%$ & & 123 & $18.6 \%$ & & \\
\hline ... Economics & 21 & $3.3 \%$ & & 12 & $1.8 \%$ & & \\
\hline ... Humanities / Arts & 126 & $19.6 \%$ & & 109 & $16.4 \%$ & & \\
\hline ... Law & 10 & $1.6 \%$ & & 16 & $2.4 \%$ & & \\
\hline ... Medical & 36 & $5.6 \%$ & & 23 & $3.5 \%$ & & \\
\hline ... Not Applicable & 104 & $16.1 \%$ & & 109 & $16.4 \%$ & & \\
\hline ... Psychology & 42 & $6.5 \%$ & & 37 & $5.6 \%$ & & \\
\hline ... Sciences / Math & 120 & $18.6 \%$ & & 132 & $19.9 \%$ & & \\
\hline ... Others & 104 & $16.1 \%$ & & 102 & $15.4 \%$ & & \\
\hline
\end{tabular}

Notes: This table shows balance of surveyed demographic and stated views between participants assigned to Large and Small groups. p-values derived from two-sample t-tests for numeric measures, and a $\chi^{2}$-test for categorical questions. The content of each of these items is shown in Appendix C in Figures A19 and A20. $* * * \mathrm{p}<.01,{ }^{* *} \mathrm{p}<0.05,{ }^{*} \mathrm{p}<.10$. 


\section{B Supplementary Theoretical Results}

\section{B.1 Results on the Fehr and Schmidt (1999) Model}

Consider a set of $n$ players indexed by $i$, and let $x_{i}$ denote player $i$ 's payoff. The standard Fehr and Schmidt (1999) model posits that utility is given by

$$
U_{i}=x_{i}-\frac{\alpha}{n-1} \sum_{j \neq i} \max \left(x_{j}-x_{i}, 0\right)-\frac{\beta}{n-1} \sum_{j \neq i} \max \left(x_{i}-x_{j}, 0\right)
$$

Now if $c\left(\pi_{i}\right)$ is the number of individuals with payoff $x_{i}=\pi_{i}$, so that $\mu\left(\pi_{i}\right)=c\left(\pi_{i}\right) / n$ is the fraction of individuals with payoff $x_{i}=\pi_{i}$, we can instead rewrite the model as

$$
\begin{aligned}
U_{i} & =x_{i}-\frac{\alpha}{n-1} \sum_{j} c\left(\pi_{j}\right) \max \left(\pi_{j}-x_{i}, 0\right)-\frac{\beta}{n-1} \sum_{j} c\left(\pi_{j}\right) \max \left(x_{i}-\pi_{j}, 0\right) \\
& =x_{i}-\frac{\alpha n}{n-1} \sum_{j} \mu\left(\pi_{j}\right) \max \left(\pi_{j}-x_{i}, 0\right)-\frac{\beta n}{n-1} \sum_{j} \mu\left(\pi_{j}\right) \max \left(x_{i}-\pi_{j}, 0\right)
\end{aligned}
$$

Finally, note that rich individuals choose to vote for redistribution if

$$
\text { (200) } \frac{\beta n}{n-1}>100
$$

i.e. if the benefit of increasing poor players' payoffs relative to oneself (left), is greater than the financial cost to oneself (right). However, poor players would vote to decrease rich players' payoffs by 100 at no cost themselves as long as $\alpha>0$. That only 11.48 percent choose to do this implies that $\alpha>0$ for only 11.48 of participants and hence $\beta>0$ for 11.48 percent. Thus, only 11.48 percent of participants could vote for redistribution in the Fehr and Schmidt (1999) model.

\section{B.2 Results on the Bolton and Ockenfels (2000) Model}

Bolton and Ockenfels (2000) propose models in which utility of a player with payoff $\pi_{i}$ is a function $U\left(\pi_{i}, \sigma_{i}\right)$,where $\sigma_{i}=\frac{\pi_{i}}{n \sum_{j} \mu\left(\pi_{j}\right) \pi_{j}}$ is player $i$ 's relative share of the pie $n \sum_{j} \mu\left(\pi_{j}\right) \pi_{j}$. Inequality aversion is captured by the assumption that $\left.\frac{\partial}{\partial \sigma} U\left(\pi_{i}, \sigma\right)\right|_{\sigma=1 / n}=0$ and that $U$ is strictly concave in $\sigma_{i}$; i.e., holding $\pi_{i}$ constant, $U$ attains its maximum at $\sigma=1 / n$, and it decreases as $\sigma$ deviates from $1 / n$. Observe that $\sigma_{i}$ is a function of $n$, not just $G$. Thus, the Bolton and Ockenfels (2000) model belongs to a more general class of models than (1), where the subutility function $v$ must take $G, \pi_{i}$, and $n$ as arguments.

Importantly, Bolton and Ockenfels (2000) is sharply inconsistent with our results. To see this, consider the decisions where the price of giving or redistribution is 100 cents to the rich players. In these decisions, first note that all forms of individual giving, as well as redistribution, have no impact on the total pie $n \sum_{j} \mu\left(\pi_{j}\right) \pi_{j}$. Second, note that in these decisions both giving or implementing redistribution have the same impact on $\pi_{i}$, and thus also on $\sigma_{i}$. Therefore, the Bolton and Ockenfels (2000) model counterfactually predicts that there should be no difference in the propensity to give in the giving to many condition and the propensity to vote on redistribution in the voting on redistribution condition. 


\section{Experimental Screenshots}

Figure A7: Introduction and Welcome

(a) Introduction: MTurk ID

To receive your bonus payment, you must enter your Mechanical Turk ID into the box below and then click $\gg$ to continue.

Your WorkerID starts with the letter A and has 12-14 letters or numbers. It is not your email address.

To ensure accuracy, please copy and paste your WorkerlD from Mturk. This makes sure that there are no mistakes (an example of a common mistake is that " 0 " (the number) is written instead of an " $\mathrm{O}$ " (the letter), or similarly).

Enter your WorkerID here: (b) Introduction: Welcome

Thank you for participating in our study. This study will take 5-10 minutes to complete. After you have finished, you will receive a completion code. Please return to the HIT on MTurk and enter the completion code in the space provided, in order to receive your credit.

You will receive $\$ 0.25$ for completing the HIT. After you have read the initial instructions, you will answer a short quiz. If you get the quiz questions right, you will receive an additional $\$ 0.15$. In addition to that, you can earn a bonus of up to $\$ 4.50$ based on the decisions you and others make.

As established researchers and long-term Requesters on Amazon MTurk, we promise that the information in this survey is truthful and accurate. We never use deception: the decisions you make are real, the group you participate in is real and we always send you the money that you earn in your interactions with others in this HIT.

If you have any questions about this research, please feel free to email us at mturk.surveys.research@gmail.com. 
Figure A8: Descriptions for Large and Small Groups

(a) Description 1: Large Group

You are going to participate in an experiment.

Your payment from the experiment will be transferred to you as a bonus on MTurk. We will now explain how the payment will be determined.

You are going to be in a group with 199 other players who are completing this hit. This means that there is a total of 200 people in your group, including you.

The experiment will consist of several parts. After all the 200 players in your group have made their decisions, we will randomly choose which part of the experiment to play out for money. All parts have equal probability to be chosen.

This means that you should consider all decisions carefully, as any one of those could be the one that determines your payoffs, and the payoffs for all the other 199 people in you group, from this HIT. (b) Description 2: Large Group

Everyone in the group will be assigned to be either an A- or a B-player. There will be 100 A-players and $100 \mathrm{~B}$-players in each group. A-players will start each part of the experiment with 350 cents and B-players will start each part with 10 cents.

It will be randomly determined if you are an A-player or a B-player.

You are going to participate in an experiment.

Your payment from the experiment will be transferred to you as a bonus on MTurk. We will now explain how the payment will be determined.

You are going to be in a group with 3 other players who are completing this hit. This means that there is a total of 4 people in your group, including you.

The experiment will consist of several parts. After all the 4 players in your group have made their decisions, we will randomly choose which part of the experiment to play out for money. All parts have equal probability to be chosen.

This means that you should consider all decisions carefully, as any one of those could be the one that determines your payoffs, and the payoffs for all the other 3 people in you group, from this HIT.

(d) Description 2: Small Group

Everyone in the group will be assigned to be either an A- or a B-player. There will be two A-players and two B-players in each group. A-players will start each part of the experiment with 350 cents and B-players will start each part with 10 cents.

It will be randomly determined if you are an A-player or a B-player. 
Figure A9: Hypothetical Role Description

(a) Hypothetical Role Description: Large Group

At this point, assume that you have been randomly chosen to be an A-player. That means that you will start each part of the experiment with 350 cents. There are a total of $100 \mathrm{~A}$ -

players in your group, including you. The other 100 players in your group are B-players who start each part of the experiment with 10 cents. (b) Hypothetical Role Description: Small Group

At this point, assume that you have been randomly chosen to be an A-player. That means that you will start each part of the experiment with 350 cents. There are a total of two Aplayers in your group, including you. The other two players in your group are B-players who start each part of the experiment with 10 cents. 
Figure A10: Comprehension Quiz Questions

(a) Quiz Questions: Large Group

Quiz - large

Out of the 200 players in your group, 100 are A-players (who start each part of the experiment with 350 cents) and 100 are B-players (who start each part of the experiment with 10 cents).

To make sure that you, and everyone else in your group, have understood the instructions, please answer the quiz questions below. You need to get these questions right in order to receive the additional payment of $\$ 0.15$ for correctly answering the quiz questions.

How many players are there in your group (in total, counting both A- and B-players)?

How many cents do the A-players in the group start each part of the experiment with?
O 10
O 200
○ 350

How many cents do the B-players in the group start each part of the experiment with?

O 10

O 200

○ 350

How many A-players and how many B-players are there in total in each group?
O 1 A-player and $1 \mathrm{~B}$-player
10 A-players and $10 \mathrm{~B}$-players
O 100 A-players and 100 B-players

At this point, which role should you assume that you have been given? (This information was given to you on the previous screen)

A-player

B-player
Figure A10: Comprehension Quiz Questions (Continued)

(b) Quiz Questions: Small Group

Quiz - small

Out of the 4 players in your group, two are A-players (who start each part of the experiment with 350 cents) and two are B-players (who start each part of the experiment with 10 cents).

To make sure that you, and everyone else in your group, have understood the instructions, please answer the quiz questions below. You need to get these questions right in order to receive the additional payment of $\$ 0.15$ for correctly answering the quiz questions.

How many players are there in your group (in total, counting both A- and B-players)?

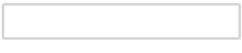

How many cents do the A-players in the group start each part of the experiment with?

$$
\begin{array}{ll}
\text { O } & 10 \\
\text { O } 200 \\
\text { O } 350
\end{array}
$$

How many cents do the B-players in the group start each part of the experiment with?

$$
\begin{aligned}
& \text { O } 10 \\
& \text { O } 200 \\
& \text { O } 350
\end{aligned}
$$

How many A-players and how many B-players are there in total in each group?

$$
\begin{aligned}
& \mathrm{O} 1 \mathrm{~A} \text {-player and } 1 \mathrm{~B} \text {-player } \\
& \mathrm{O} 1 \mathrm{~A} \text {-player and } 2 \text { B-players } \\
& \mathrm{O} 2 \mathrm{~A} \text {-players and } 2 \text { B-players }
\end{aligned}
$$

At this point, which role should you assume that you have been given? (This information was given to you on the previous screen) 
Figure A11: Scenarios Introduction

(a) Scenarios Introduction: Large Group

You will now see nine different screens that describe nine different scenarios. Please answer the question about how you want to act in each scenario. The scenarios may sometimes seem similar, so make sure to read carefully so that you see the differences between them.

Remember that one of these scenarios will be selected at random and be played out for money (all have equal probability of being selected). Therefore, please consider all

decisions carefully as any one of them may be the one that determines your payoffs and the payoffs of the other 199 people in your group.

\section{(b) Scenarios Introduction: Small Group}

You will now see nine different screens that describe nine different scenarios. Please answer the question about how you want to act in each scenario. Remember that one of these scenarios will be selected at random and be played out for money (all have equal probability of being selected). Therefore, please consider all decisions carefully as any one of them may be the one that determines your payoffs and the payoffs of the other 3 people in your group.

Figure A12: Giving to Many

(a) Giving to Many: Large Group

This is scenario $X$ of 9 .

In this scenario, you and the other 99 A-players (you all start with 350 cents each) will each individually choose whether or not to spend [80/100/120] cents to increase each of the 100 B-players' payoff by 1 cent. The B-players have 10 cents to start and will make no decision in this part.

No

Do you want to spend

$[80 / 100 / 120]$ of your

each B-player's payo

by 1 cent?

(b) Giving to Many: Small Group

This is scenario $\mathrm{X}$ of 9 .

In this scenario, you and the other A-player (you both start with 350 cents each) will each individually choose whether or not to spend [80/100/120] cents to increase each of the two B-players' payoff by 50 cents. The B-players have 10 cents to start and will make no decision in this part.

Do you want to spend $[80 / 100 / 120]$ of your

350 cents to increase each B-player's payo 
Figure A13: Giving to One of Many

(a) Giving to One of Many: Large Group

This is scenario $X$ of 9 .

In this scenario, you and the other $99 \mathrm{~A}$-players (you all start with 350 cents each) will each individually choose whether or not to spend [80/100/120] cents to increase a random one of the hundred B-players' payoff by 100 cents. The computer will make sure that no Bplayer can get more than 100 cents. The B-players have 10 cents to start and will make no decision in this part.

Yes

No

Do you want to spend

$[80 / 100 / 120]$ of your

350 cents to increase

a random one of the

payoff by 100 cents?

(b) Giving to One of Many: Small Group

This is scenario $X$ of 9 .

In this scenario, you and the other A-player (you both start with 350 cents each) will each individually choose whether or not to spend [80/100/120] cents to increase a random one of the two B-players' payoff by 100 cents. The computer will make sure that no B-player can get more than 100 cents. The B-players have 10 cents to start and will make no decision in this part. Do you want to spend
[80/100/120] of your 350 cents to increase a random one of the two B-players' payoff by 100 cents?
Figure A14: Giving to One Partner

(a) Giving to One Partner: Large Group

This is scenario $X$ of 9 .

In this scenario, you and the other $99 \mathrm{~A}$-players (you all start with 350 cents each) will each be paired with one $B$ player. You will individually choose whether or not to spend [80/100/120] cents to increase your paired B-player's payoff by 100 cents. Each B-player will be paired with exactly one A-player. The B-players have 10 cents to start and will make no decision in this part.
O
Do you want to spend

[80/100/120] of your

350 cents to increase

payoff by 100 cents? your paired B-player's

This is scenario $X$ of 9 .

In this scenario, you and the other A-player (you both start with 350 cents each) will each be paired with one $B$ player. You will individually choose whether or not to spend [80/100/120] cents to increase your paired B-player's payoff by 100 cents. Each B-player will be paired with exactly one A-player. The B-players have 10 cents to start and will make no decision in this part.
Yes
Do you want to spend

350 cents to of your

your paired B-player's

payoff by 100 cents? 
Figure A15: Voting on Redistribution

(a) Voting on Redistribution: Large Group

This is scenario $X$ of 9 .

In this scenario, you and the other 99 A-players (you all start with 350 cents each) will vote about whether or not all of the A-players should spend [80/100/120] cents each to increase the 100 B-players' payoff by 100 cents each. The B-players start with 10 cents and will not vote in this part.

If a majority of the A-players vote for the transfer it will be implemented, otherwise it will not be implemented. If exactly half (i.e. 50 ) of the A-players vote for this transfer, it will be randomly determined if it is implemented or not.

Now please make your decision: do you want to vote for or against each of the Bplayers getting 100 cents at a cost of [80/100/120] cents to each of the A-players?

O For

Against

(b) Voting on Redistribution: Small Group

This is scenario $X$ of 9 .

In this scenario, you and the other A-player (you both start with 350 cents each) will vote about whether or not both of the A-players should spend [80/100/120] cents each to

increase the two B-players' payoff by 100 cents each. The B-players start with 10 cents and will not vote in this part.

If a majority of the A-players vote for the transfer it will be implemented, otherwise it will not be implemented. If exactly half (i.e. one) of the A-players vote for this transfer, it will be randomly determined if it is implemented or not.

Now please make your decision: do you want to vote for or against each of the Bplayers getting 100 cents at a cost of [80/100/120] cents to each of the A-players?

\section{O For}

Against
Figure A16: Decision as a B-player (poor)

(a) Decision as a B-player: Large Group

You have now made decisions in all scenarios under the assumption that you are randomly selected to be one of the $100 \mathrm{~A}$-players.

It is, however, equally likely that you are randomly selected to be one of the $100 \mathrm{~B}$-players. If you are assigned to be a B-player you just have one decision to make.

In this part, you and the other 99 B-players (you all start with 10 cents each) will vote about whether or not all of the A-players should get 100 cents less (without the B-players getting anything extra). The A-players start with 350 cents and will not vote in this part.

If a majority of the B-players vote for this, it will be implemented and the A-players will have $350-100=250$ cents each, and the B-players will have 10 cents each. If a majority of the B-players vote against this, it will not be implemented and the A-players will have 350 cents and the B-players will have 10 cents. If exactly half (i.e. 50 ) B-players vote for this transfer, it will be randomly determined if it is implemented or not.

Now please make your decision: do you want to vote for or against each of the Aplayers getting 100 cents less without the B-players getting anything extra?

O For

Against

(b) Decision as a B-player: Small Group

You have now made decisions in all scenarios under the assumption that you are randomly selected to be one of the two A-players.

It is, however, equally likely that you are randomly selected to be one of the two B-players. If you are assigned to be a B-player you just have one decision to make.

In this part, you and the other B-player (you both start with 10 cents each) will vote abou whether or not both of the A-players should get 100 cents less (without the B-players getting anything extra). The A-players start with 350 cents and will not vote in this part.

If a majority of the B-players vote for this, it will be implemented and the A-players will have $350-100=250$ cents each, and the B-players will have 10 cents each. If a majority of conts and the B-players will have 10 cents. If exactly half $(\mathrm{fe}$, one of the B-players vote for this transfer, it will be randomly determined if it is implemented or not.

Now please make your decision: do you want to vote for or against both of the Aplayers getting 100 cents less without the B-players getting anything extra? 
Figure A17: Dictator Game

This is the last question where you can earn money. This part has a 20 percent probability to be played out for money, and it is independent of the other scenarios that you provided answers to.

In this part you are paired with one other survey respondent. This may or may not be someone who was in your group in the previous part of the experiment.

In this game one of you in the pair will be allocated 100 cents. The other person will be allocated zero cents.

The person who has 100 cents can decide what amount of cents, between 0 and 100, to allocate to the other person in the pair. The rest you will keep for yourself.

If you are the person who has 100 cents, what amount do you want to transfer to the other person in the pair:

\section{Figure A18: End of Experiment Message}

The experiment is now over. Your earnings will be transferred to you as a bonus on mturk.

We now ask you to please answer some questions before we provide you with the completion code for the hit. 
Figure A19: Politics Questionnaire

When it comes to social issues, how liberal or conservative are you?

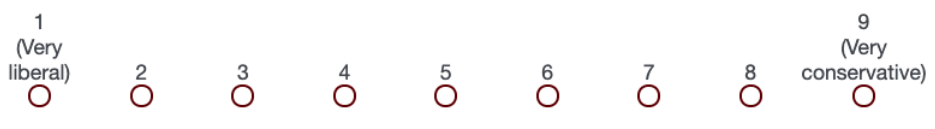

When it comes to economic issues, how liberal or conservative are you?

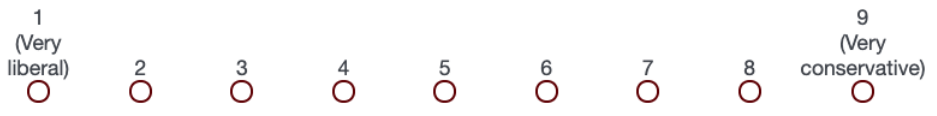

Which political party do you more strongly identify with?

Democrat

$\underset{v}{\omega}$

Republican

Independent

How strongly do you affiliate with this party?

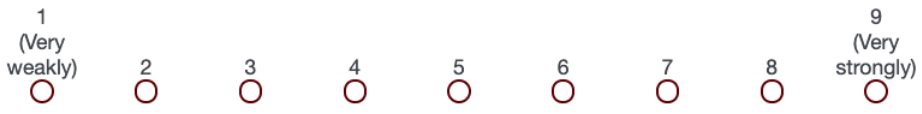

Figure A19: Politics Questionnaire (Continued)

Do you think that the redistribution of economic resources from those with more resources to those with less resources is an important part of the government's job?

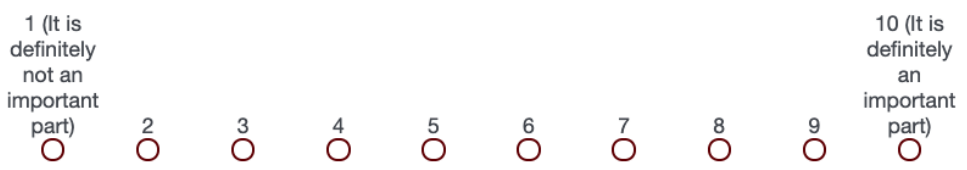

Compared to the current situation, do you think that there should be more or less redistribution of resources from those in the US who have more monetary resources (income and/or wealth) to those who have less?

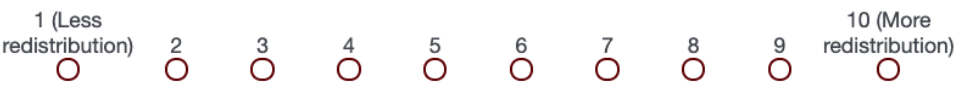

To the extent that you think that resources should be redistributed between people in the US, who do you think should be mainly responsible for making sure that this redistribution happens?

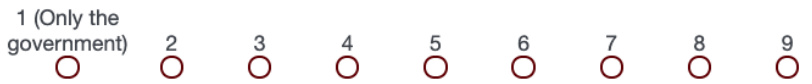

10 (Only charitable organizations or other private initiatives)

To what extent do you think that an individual's economic success or failure can be attributed to personal effort and to luck?

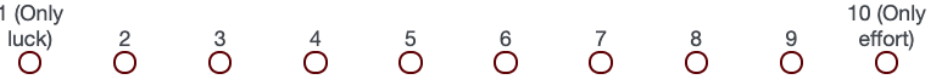

| 
Figure A20: Demographics Questionnaire

To what extend have you participated in other studies involving the dividing up of money on MTurk before taking this HIT?

\begin{tabular}{ccccc}
1 - Never & 2 & 3 - Sometimes & 4 & 5 - Very often \\
\hline & 0 & $O$ & $O$
\end{tabular}

What is your age (in years)?

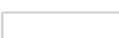

What is your gender?

\section{Male}

O Female

$\mathrm{O}$ I do not identify myself as male or female.

Ethnicity:

\section{Asian \\ O Black}

O Hispanic-Latino

O Native American

White

Other

What is your country of residence?

United States

Canada

O India

Other
Figure A20: Demographics Questionnaire (Continued)

Are you currently a student?

$\mathrm{O}$ Yes

No

Are you currently married and living with the person you are married to, or are you living in a marriage-like relationship with your partner?

$\mathrm{O}$ Yes

No

What was your total personal income last year? Take into account all your sources of income, including scholarships, health benefits, fringe benefits, and others. Please note that this is your personal income, not the income of your household.
O Less than $\$ 10,000$
O $\$ 10,000$ to $\$ 20,000$
$\mathrm{O} \$ 20,000$ to $\$ 30,000$
O $\$ 30,000$ to $\$ 40,000$
$\mathrm{O} \$ 40,000$ to $\$ 50,000$
O $\$ 50,000$ to $\$ 60,000$
O $\$ 60,000$ to $\$ 70,000$
O $\$ 70,000$ to $\$ 80,000$
O $\$ 80,000$ to $\$ 90,000$
O $\$ 90,000$ to $\$ 100,000$
Over $\$ 100,000$ 
Figure A20: Demographics Questionnaire (Continued)

In case your household consists of more people that you, what was the total income of

your household last year? Take into account all sources of income, including scholarships,

health benefits, fringe benefits, and others. Please note that this the income of your

household.

O Less than $\$ 20,000$

O $\$ 20,000$ to $\$ 40,000$

O $\$ 40,000$ to $\$ 60,000$

O $\$ 60,000$ to $\$ 80,000$

$\mathrm{O} \$ 80,000$ to $\$ 100,000$

O $\$ 100,000$ to $\$ 120,000$

O $\$ 120,000$ to $\$ 140,000$

O $\$ 140,000$ to $\$ 160,000$

$\$ 160,000$ to $\$ 180,000$

$\$ 180,000$ to $\$ 200,000$

O Over $\$ 200,000$

The question does not apply to me because l am the only person in my household.

What is your highest level of education completed?

$O$ Less than a high school degree

O High School Diploma

Vocational Training

O Attended College

Bachelor's Degree

O Graduate Degree

What was/is your major in college/graduate school?

E Economics

Psychology

O Sciences / Math

O Humanities / Arts

O Business / MBA

O Medical

$O$ others

Not applicable

Was anything unclear in the instructions or survey questions? (Optional) 